\title{
The Solubilities of Significant Organic Compounds in HLW Tank Supernate Solutions - FY 1997 Progress Report
}

\author{
G. S. Barney \\ B\&W Hanford Company \\ Date Published \\ September 1997
}

Prepared for the U.S. Department of Energy

Project Hanford Management Contractor for the

U.S. Department of Energy under Contract DE-ACO6-96RL13200

Approved for public release; distribution is unlimited 


\section{LEGAL DISCLAIMER}

This report was prepared as an account of work sponsored by an agency of the United States Government. Neither the United States Government nor any agency thereof, nor any of their employees, nor any of their contractors, subcontractors or their employees, makes any warranty, express or implied, or assumes any legat.liability or responsibility for the accuracy, completeness, or any third party's use or the results of such use of any information, apparatus, product, or process disclosed, or represent's that its use would not infringe privately owned rights. Reference herein to any specifio commercial product, process, or service by trade name, trademark, manufacturer, or otherwise, does not necessarily constitute or imply its endorsement, recommendation, or favoring by the United States Government or any agency thereof or its contractors or subcontractors. The views and opinions of authors expressed herein do not necessarily state or reflect those of the United States Government or any agency thereof.

This report has been reproduced from the best available copy. Available in paper copy and microfiche.

Avalable to the U.S. Department of Energy and its contractors from

U.S. Department of Energy

Office of Scientific and Technical Information (OST)

P.O. Box 62

Oäk Ridge, TN 37831

(615) 576-8401

Available to the public from the U.S. Department of Commerce National Technical Information Service (NTIS)

5285 Port Royal Road

Springfield, VA 22161

(703) 487-4650

Printed in tho United States of America

DISCLM-1.CHP (8-95) 


\section{RELEASE AUTHORIZATION}

Document Number: HNF-EP-0899-2

The Solubilities of Significant Organic Compounds in HLW Tank Supernate Solutions - FY1997 Progress Report

Release Date: $\quad 9 / 16 / 97$

This document was reviewed following the procedures described in WHC-CM-3-4 and is:

APPROVED FOR PUBLIC RELEASE

WHC Information Release Administration Specialist:

C.


HNF-EP-0899-2

\title{
THE SOLUBILITIES OF SIGNIFICANT ORGANIC COMPOUNDS IN HLW TANK SUPERNATE SOLUTIONS -- FY1997 PROGRESS REPORT
}

\author{
G. S. Barney
}

ABSTRACT

The solubilities of seven sodium salts of organic acids that are thought to exist in high-level waste at the Hanford Site were measured in tank supernate simulant solutions during FY1997. This solubility information will be used to determine if these organic salts could exist in solid phases (saltcake or sludges) in the waste where they might react violently with the nitrate or nitrite salts present in the tanks. The solubility of sodium acetate was measured in simulated waste supernate solutions at $25^{\circ} \mathrm{C}, 30^{\circ} \mathrm{C}, 40^{\circ} \mathrm{C}$, and $50^{\circ} \mathrm{C}$ that were both unsaturated and saturated with sodium nitrate. Solubilities of sodium glycolate, citrate, ethylendiaminetetraacetate (EDTA), nitrilotriacetate (NTA), formate, and oxalate were measured in simulated waste supernate solutions that were saturated with sodium nitrate. In addition, solubilities of sodium EDTA, citrate, glycolate, and NTA were measured in a complex waste matrix. The organic compounds were selected because they are expected to exist in relatively high concentrations in the tanks. The solubilities of sodium glycolate, citrate, EDTA, NTA, and formate were high over the temperature and sodium hydroxide concentration ranges expected in the tanks. The solubility of sodium oxalate in solutions saturated with sodium nitrate were quite low. The presence of additional sodium in the waste simulant solutions that were saturated with sodium nitrate slightly lowered the solubilities of each of the organic salts. Solubilities were, however, high enough to prevent solid sodium salts of all the organic acids from precipitating from tank supernate solutions, except for sodium oxalate. The total organic carbon concentrations (TOC) of actual tank supernates are 


\section{HNF-EP-0899-2}

generally much lower than the TOC ranges for the simulated supernate solutions saturated (at the solubility limit) with the organic salts. This is true even if all the dissolved carbon in a given tank supernate is due to only one of these soluble compounds (an unlikely situation). Solubilities of all the organic salts, except for glycolate, decrease with increasing sodium hydroxide and sodium nitrate concentration because of the common ion effect of $\mathrm{Na}^{+}$. Sodium glycolate solubility increased with increasing hydroxide concentration. The complex waste solutions had sodium ion concentrations 3.4 to 7.0 molar higher than unsaturated solutions. This caused a significant lowering of the solubilities of the organic sodium salts due to the common ion effect of sodium.

Results of EDTA adsorption measurements show that EDTA or EDTA-metal complexes can be adsorbed onto hydrous metal oxides (that make up the siudge layers in the tanks) under conditions simulating the high-level waste tanks. The extent of adsorption is not large and depends on the concentration of hydroxide in the waste solutions. Higher hydroxide concentrations lower adsorption of EDTA. Adsorption also depends on the type of metal hydrous oxide present. Adsorption data for $\mathrm{Fe}(I I I), \mathrm{Cr}(\mathrm{III})$, and Ni(II) hydrous oxides show that chromium(III) hydrous oxide adsorbs EDTA most effectively. 


\section{CONTENTS}

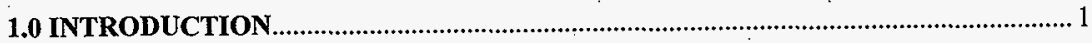

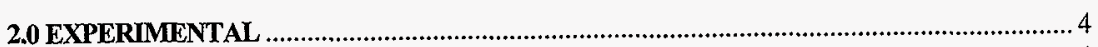

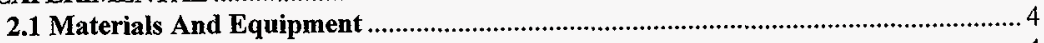

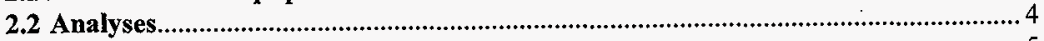

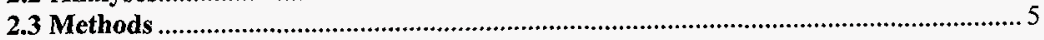

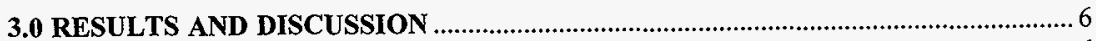

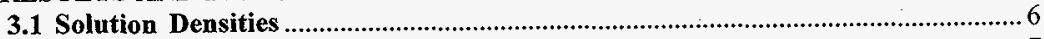

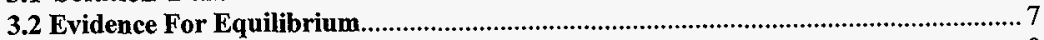

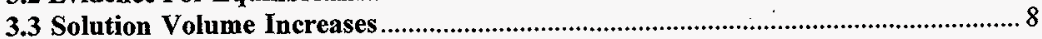

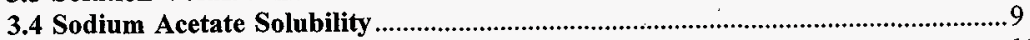

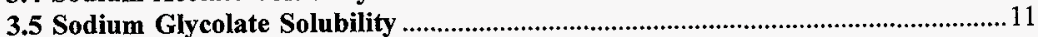

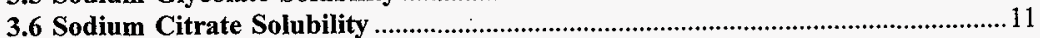

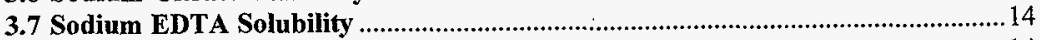

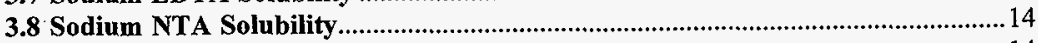

3.9 Sodium Formate Solubility ......................................................................... 14

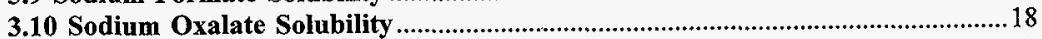

3.11 EDTA Adsorption on Metal Hydrous Oxides ................................................. 18

3.12 Solubilities in Complex Waste Mixtures..........................................................23

3.13 HLW Tank Total Organic Carbon Values ........................................................28

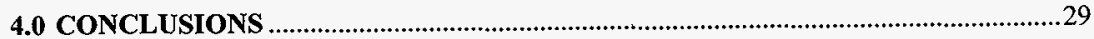

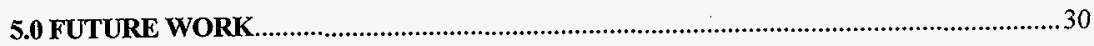

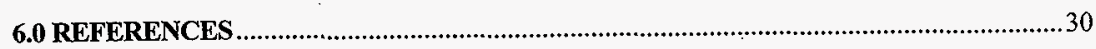

APPENDIX - Solubilities of Organic Salts and Solution Compositions.......................A-1 


\section{LIST OF FIGURES}

Figure 3-1 Solubility of sodium acetate in $\mathrm{NaNO}_{3}-\mathrm{NaNO}_{2}$ solutions at $25^{\circ} \mathrm{C}, 30^{\circ} \mathrm{C}, 40^{\circ} \mathrm{C}$, and $50^{\circ} \mathrm{C}$ for various sodium hydroxide concentrations.

Figure 3-2 Solubility of sodium acetate in $\mathrm{NaNO}_{3}-\mathrm{NaNO}_{2}$ solutions saturated with crystalline $\mathrm{NaNO} 3$ at $25^{\circ} \mathrm{C}, 30^{\circ} \mathrm{C}, 40^{\circ} \mathrm{C}$, and $50^{\circ} \mathrm{C}$ for various sodium hydroxide concentrations $(\mathrm{A})$, and measured sodium nitrate concentrations in the same solutions (B). . .10

Figure 3-3 Solubility of sodium glycolate in $\mathrm{NaNO}_{3}-\mathrm{NaNO}_{2}$ solutions saturated with crystalline $\mathrm{NaNO}_{3}$ at $25^{\circ} \mathrm{C}, 30^{\circ} \mathrm{C}, 40^{\circ} \mathrm{C}$, and $50^{\circ} \mathrm{C}$ for various sodium hydroxide concentrations (A), and measured sodium nitrate concentrations in the same solutions (B).

Figure 3-4 Solubility of sodium citrate in $\mathrm{NaNO}_{3}-\mathrm{NaNO}_{2}$ solutions saturated with crystalline $\mathrm{NaNO}_{3}$ at $25^{\circ} \mathrm{C}, 30^{\circ} \mathrm{C}, 40^{\circ} \mathrm{C}$, and $50^{\circ} \mathrm{C}$ for various sodium hydroxide concentrations (A), and measured sodium nitrate concentrations in the same solutions (B).

Figure 3-5 Solubility of sodium EDTA in $\mathrm{NaNO}_{3}-\mathrm{NaNO}_{2}$ solutions saturated with crystalline $\mathrm{NaNO} 3$ at $25^{\circ} \mathrm{C}, 30^{\circ} \mathrm{C}, 40^{\circ} \mathrm{C}$, and $50^{\circ} \mathrm{C}$ for various sodium hydroxide concentrations $(\mathrm{A})$, and measured sodium nitrate concentrations in the same solutions (B).

Figure 3-6 Solubility of sodium $\mathrm{NTA}_{\text {in }} \mathrm{NaNO}_{3}-\mathrm{NaNO}_{2}$ solutions saturated with crystalline $\mathrm{NaNO}_{3}$ at $25^{\circ} \mathrm{C}, 30^{\circ} \mathrm{C}, 40^{\circ} \mathrm{C}$, and $50^{\circ} \mathrm{C}$ for various sodium hydroxide concentrations $(\mathrm{A})$, and measured sodium nitrate concentrations in the same solutions (B).

Figure 3-7 Solubility of sodium formate in $\mathrm{NaNO}_{3}-\mathrm{NaNO}_{2}$ solutions saturated with crystalline $\mathrm{NaNO}_{3}$ at $25^{\circ} \mathrm{C}, 30^{\circ} \mathrm{C}, 40^{\circ} \mathrm{C}$, and $50^{\circ} \mathrm{C}$ for various sodium hydroxide concentrations $(\mathrm{A})$, and measured sodium nitrate concentrations in the same solutions (B).

Figure 3-8 Solubility of sodium oxalate in $\mathrm{NaNO}_{3}-\mathrm{NaNO}_{2}$ solutions saturated with crystalline $\mathrm{NaNO}_{3}$ at $25^{\circ} \mathrm{C}, 30^{\circ} \mathrm{C}, 40^{\circ} \mathrm{C}$, and $50^{\circ} \mathrm{C}$ for various sodium bydroxide concentrations (A), and measured sodium nitrate concentrations in the same solutions (B).

Figure 3-9 Adsorption of EDTA on precipitated ferric hydroxide in $4.2 \mathrm{M} \mathrm{NaNO}_{3}$ solutions at $25^{\circ} \mathrm{C}$ for various sodium hydroxide concentrations and initial tetrasodium EDTA concentrations of $0.1 \mathrm{M}, 0.01 \mathrm{M}$, and $0.001 \mathrm{M}$.(B). 
HNF-EP-0899-2

\section{LIST OF FIGURES (Cont.)}

Figure 3-10 Adsorption of EDTA on precipitated chromic hydroxide in 4.2 $\mathrm{M} \mathrm{NaNO}_{3}$ solutions at $25^{\circ} \mathrm{C}$ for various sodium hydroxide concentrations and initial tetrasodium EDTA concentrations of $0.1 \mathrm{M}, 0.01 \mathrm{M}$, and $0.001 \mathrm{M}$.(B).

Figure 3-11 Adsorption of EDTA on precipitated nickel hydroxide in 4.2 $\mathrm{M} \mathrm{NaNO} 3$ solutions at $25^{\circ} \mathrm{C}$ for various sodium hydroxide concentrations and initial tetrasodium EDTA concentrations of $0.1 \mathrm{M}, 0.01 \mathrm{M}$, and $0.001 \mathrm{M}$.(B)

Figure 3-12 Solubility of sodium glycolate in different waste simulant solution matrices at $40^{\circ} \mathrm{C}$ and $50^{\circ} \mathrm{C}$ over a range of sodium hydroxide concentrations.

Figure 3-13 Solubility of sodium citrate in different waste simulant solution matrices at $40^{\circ} \mathrm{C}$ and $50^{\circ} \mathrm{C}$ over a range of sodium hydroxide concentrations.

Figure 3-14. Solubility of sodium EDTA in different waste simulant solution matrices at $40^{\circ} \mathrm{C}$ and $50^{\circ} \mathrm{C}$ over a range of sodium hydroxide concentrations.

Figure 3-15 Solubility of sodium NTA in different waste simulant solution matrices at $40^{\circ} \mathrm{C}$ and $50^{\circ} \mathrm{C}$ over a range of sodium hydroxide concentrations.

Figure 3-16 Frequency distribution of total organic carbon (TOC) concentrations measured in supernate solutions in 61 different Hanford Site HLW tanks .28 
HNF-EP-0899-2

\section{LIST OF TABLES}

Table 1-1 Organic compounds selected for solubility studies.

Table 3-1 Densities of the simulated supernate solutions and supernate solutions saturated with organic salts at $25^{\circ} \mathrm{C}$ to $50^{\circ} \mathrm{C}$

Table 3-2 Average concentrations of organics versus time over all sodium hydroxide concentrations .8

Table 3-3 Volume increases due to dissolution of sodium acetate and sodium acetate + sodium nitrate.

Table 3-4 Components of simulated complex waste mixtures......................................................24

Table 3.5 Equilibrium concentrations of complex waste mixture components.............................25

Table 3.6 Average total sodium ion molarities for different solution matricies. ..........................25

Table 3-7 Comparison of measured organic sodium salt solubilities in units of molarity and total organic carbon concentrations (TOC) 
HNF-EP-0899-2

\section{ACRONYMS AND TERMS}

$\begin{array}{ll}\text { DBP } & \text { dibutyl phosphate } \\ \text { DSS } & \text { double-shell slurry } \\ \text { EDTA } & \text { ethylenediaminetetraacetate } \\ \text { ED3A } & \text { ethylenediaminetriacetate } \\ \text { HDBP } & \text { dibutyl phosphoric acid } \\ \text { HEDTA } & \text { N-(2-hydroxyethyl)ethylenediaminetriacetate } \\ \text { HLW } & \text { high-level waste } \\ \text { IDA } & \text { iminodiacetate } \\ \text { NTA } & \text { nitrilotriacetate } \\ \text { TBP } & \text { tributyl phosphate } \\ \text { TOC } & \text { total organic carbon } \\ \text { NPH } & \text { normal parrafin hydrocarbon } \\ \text { NCRW } & \text { neutralized cladding removal waste }\end{array}$




\title{
THE SOLUBILITIES OF SIGNIFICANT ORGANIC COMPOUNDS IN HLW TANK SUPERNATE SOLUTIONS -- FY1997 PROGRESS REPORT
}

\author{
G. S. Barney
}

\subsection{INTRODUCTION}

This report is a summary of work completed in FY1997 on the measurement of solubilities of organic compounds found in high-level waste (HLW) supernate solutions at Hanford. Earlier reports (Barney 1994, 1995, and 1996) presented the solubilities of eleven sodium salts of organic acids that are known to exist in the wastes [sodium oxalate, formate, citrate, ethylenediaminetetraacetate (EDTA), nitrilotriacetate (NTA), glycolate, succinate, caproate, dibutyl phosphate, butyrate, and N-(2-hydroxyethyl)ethylenediamimetriacetate (HEDTA)]. Solubilities of aluminum oxalate and iron and aluminum dibutyl phosphate compounds were also measured in simulated supernate solutions. This document reports laboratory solubility measurements for (1) sodium acetate in simulated waste supernate solutions not saturated with sodium nitrate, (2) sodium acetate, glycolate, citrate, formate, EDTA, NTA, and oxalate in simulatated supernate solutions saturated with sodium nitrate, and (3) sodium glycolate, citrate, EDTA, and NTA in a simulated complex mixture of waste components. Solubility measurements for additional compounds (sodium laurate, iminodiacetate (IDA), bis(2-ethylhexyl) phosphate and two-component organic salt mixtures) are in various stages of completion and will be documented later.

The overall objective for these solubility measurements is to obtain solubility data that will allow prediction of whether or not significant quantities of organics exist as solids in the HLW tanks. Knowledge of which phase (liquid or solid) the organic compounds are in is important to safety analyses of the waste tanks and also to operations where the phases are separated (salt well pumping, evaporation-crystallization, etc.). These data will also allow better estimates of how organic compounds in the wastes were distributed to different tanks after transfer operations.

The safety concern for tanks containing high concentrations of organic compounds is that the organics might react violently with nitrate or nitrite salts, which are also present in the tanks, to produce heat and pressure from gaseous reaction products. The organic compounds and oxidizing salts must be present mainly in a solid form and the organic compounds must be present in a minimum concentration for a hazardous, self-propagating reaction to occur. The preliminary safety criteria (Webb et al. 1995) indicate that any waste organic-nitrite/nitrate mixture containing water concentrations greater than $20 \%$ by weight is safe and will not propagate. At or below this water concentration, the organic compounds in the waste must be present mainly as solids at the minimum total organic carbon (TOC) concentration range $(4.5 \%$ to $7.9 \%$ by weight, depending on water content) that allows propagating reactions. The solubilities of the organic compounds in the waste supernate solutions must therefore be exceeded to have a propagating mixture present in the waste. If the organic solubilities are known and are compared 
with concentrations found in the waste supernate solutions, the presence of solid organic compounds can be predicted.

Prior measurements of the solubilities of sodium salts of formic acid, citric acid, EDTA, HEDTA, NTA, glycolic acid, succinic acid, butyric acid, caproic acid, and dibutyl phosphoric acid (Barney 1994, 1995, and 1996) show that they are quite soluble in simulated supernate solutions. Their solubilities are much higher than any known TOC measurements of actual waste tank supernate solutions. This observation leads to the conclusion that none of these salts exist as solids in the tanks and that they will not form a propagating mixture. This, of course, assumes that the tank supernates analyzed are in equilibrium with the solid waste mixtures. Sodium oxalate solubilities were found to be relatively low and this compound will precipitate from some tank supernate solutions. The energy content of sodium oxalate is small, however.

Analyses of the organic components of several high-level wastes from different Hanford Site tanks have identified significant compounds. Campbell et al. (1994, 1995, and 1996) analyzed core segments from tanks 241-SY-101, 241-SY-103, 241-C-106, and 241-C-204 and found the major organic components to be salts of chelating agents, low molecular weight carboxylic acids, bis(2-ethylhexyl) phosphoric acid and tributyl phosphate. The major chelating compounds were EDTA, NTA, citric acid, iminodiacetic acid (IDA), succinic acid, and ethylenediaminetriacetic acid (ED3A). The major low molecular weight carboxylic acids were oxalic, formic, glycolic, and acetic acids. Toste et al. (1988) identified organic compounds in a neutralized cladding removal waste (NCRW) and a double-shell slurry waste (DSS). They found citric acid, EDTA, tributyl phosphate, long chain hydrocarbons, and long chain carboxylic acids to be the major compounds present. Work at Georgia Institute of Technology (Ashby et al. 1994) and the Pacific Northwest National Laboratory (Camaioni et al. 1995 and 1996) on waste tank simulants and actual wastes suggest that complexants in the tank wastes degrade by carbon-nitrogen bond scission followed by oxidation of the reactive intermediates to carboxylic acids. Ultimately, oxalate, formate and carbonate are produced.

Sodium acetate has been identified in tank 241-SY-103 and 241-SY-101wastes by Campbell et al.(1995). Acetate is a likely degradation product of the chelating agents used in chemical processing at Hanford. The solubility of this compound and the others studied in FY1997 were measured in simulated HLW supernate solutions containing sodium nitrate, sodium nitrite, and sodium hydroxide, which are major components of the HLW. Three simulant solutions were used: (1) a solution with initial concentrations of $4.0 \mathrm{M}$ sodium nitrate, $0.97 \mathrm{M}$ sodium nitrite, and sodium hydroxide concentrations ranging from $0.00003 \mathrm{M}$ to $2.0 \mathrm{M}$, (2) a $2.0 \mathrm{M}$ sodium nitrite solution saturated with crystalline sodium nitrate and sodium hydroxide concentrations ranging form $0.1 \mathrm{M}$ to $2.0 \mathrm{M}$, and (3) a complex solution saturated with sodium nitrate, carbonate, sulfate, phosphate, four organic salts, and a number of metal hydrous oxides. Temperatures during solubility measurements were controlled to $\pm 0.1{ }^{\circ} \mathrm{C}$ over the range of $25^{\circ} \mathrm{C}$ to $50^{\circ} \mathrm{C}$. These values approximate conditions expected in the tanks so that the solubility data can be used to estimate solubilities in the actual wastes.

It is known that large quantities of $\mathrm{N}$-(2-hydroxethyl)ethylenediaminetriacetate (HEDTA), ethylenediaminetetraacetate (EDTA), glycolate, and citric acid were added to the tanks as a result of chemical processing at B-Plant. Smaller quantities of tributyl phosphate 
(TBP), normal paraffin hydrocarbons (NPH), oxalate, di-2-ethylhexylphosphate, and dibutylbutylphosphonate were also added, as well as small quantities of many other organic compounds. Chemical and radiolytic degradation of some of these compounds has occurred over the years to produce a complex mixture of organic degradation products. Some of these products are known, but many are unknown and need to be identified. The organic compounds to be examined in these studies were chosen because (1) they were added to the tanks in large quantities, (2) they are likely degradation products of major organic compounds added to the tanks, or (3) they have been found in significant quantities by chemical analysis of the waste. The organic compounds selected for solubility measurements are given in Table 1-1. Very little information on the solubilities of these compounds is available in the chemical literature.

Table 1-1. Organic compounds selected for solubility studies.

\begin{tabular}{|c|c|c|c|}
\hline Compound Name & Compound Formula & Source & Identified in Waste? \\
\hline Sodium Formate & $\mathrm{NaCHO}_{2}$ & Degradation Product & Yes \\
\hline Sodium Acetate & $\mathrm{NaC}_{2} \mathrm{H}_{3} \mathrm{O}_{2} \cdot 3 \mathrm{H}_{2} \mathrm{O}$ & Degradation Product & Yes \\
\hline Sodium Butyrate & $\mathrm{NaC}_{4} \mathrm{H}_{7} \mathrm{O}_{2}$ & $\begin{array}{l}\text { Possible Degradation Product of } \\
\text { TBP, NPH or MIBK }\end{array}$ & No \\
\hline $\begin{array}{l}\text { Sodium Caproate } \\
\text { (Hexanoate) }\end{array}$ & $\mathrm{NaC}_{6} \mathrm{H}_{11} \mathrm{O}_{2}$ & $\begin{array}{l}\text { Possible Degradation Product of } \\
\text { NPH }\end{array}$ & No \\
\hline Sodium Laurate & $\mathrm{NaC}_{12} \mathrm{H}_{23} \mathrm{O}_{2}$ & $\begin{array}{l}\text { Possible Degradation Product of } \\
\text { NPH }\end{array}$ & No \\
\hline Sodium Palmitate & $\mathrm{NaC}_{16} \mathrm{H}_{31} \mathrm{O}_{2}$ & $\begin{array}{l}\text { Possible Degradation Product of } \\
\text { NPH }\end{array}$ & No \\
\hline Sodium Glycolate & $\mathrm{NaC}_{2} \mathrm{H}_{3} \mathrm{O}_{3}$ & Process Reagent & Yes \\
\hline Disodium Oxalate & $\mathrm{Na}_{2} \mathrm{C}_{2} \mathrm{O}_{4}$ & $\begin{array}{l}\text { Degradation Product and Process } \\
\text { Reagent }\end{array}$ & Yes \\
\hline Disodium Succinate & $\mathrm{Na}_{2} \mathrm{C}_{4} \mathrm{H}_{4} \mathrm{O}_{4} \cdot 6 \mathrm{H}_{2} \mathrm{O}$ & Degradation Product & Yes \\
\hline Trisodium Citrate & $\mathrm{Na}_{3} \mathrm{C}_{6} \mathrm{H}_{5} \mathrm{O}_{7} \cdot 2 \mathrm{H}_{2} \mathrm{O}$ & Process Reagent & Yes \\
\hline Trisodium Nitrilotriacetate & $\mathrm{Na}_{3} \mathrm{NC}_{6} \mathrm{H}_{6} \mathrm{O}_{6} \cdot \mathrm{H}_{2} \mathrm{O}$ & Process Reagent & Yes \\
\hline $\begin{array}{l}\text { Tetrasodium Ethylenedi- } \\
\text { aminetetraacetate }\end{array}$ & $\mathrm{Na}_{4} \mathrm{~N}_{2} \mathrm{C}_{10} \mathrm{H}_{12} \mathrm{O}_{8} \cdot 2 \mathrm{H}_{2} \mathrm{O}$ & Process Reagent & Yes \\
\hline Disodium Iminodiacetate & $\mathrm{Na}_{2} \mathrm{C}_{4} \mathrm{H}_{7} \mathrm{O}_{4} \mathrm{~N} \cdot \mathrm{H}_{2} \mathrm{O}$ & Degradation Product & Yes \\
\hline $\begin{array}{l}\text { Disodium Ethylene- } \\
\text { diaminediacetate }\end{array}$ & $\mathrm{Na}_{2} \mathrm{C}_{6} \mathrm{H}_{10} \mathrm{O}_{4} \mathrm{~N}_{2}$ & Degradation Product & Yes \\
\hline $\begin{array}{l}\text { Trisodium N-(2-Hydroxy- } \\
\text { ethylenediaminetriacetate }\end{array}$ & $\mathrm{Na}_{3} \mathrm{C}_{10} \mathrm{H}_{15} \mathrm{~N}_{2} \mathrm{O}_{7} \cdot 2 \mathrm{H}_{2} \mathrm{O}$ & Process Reagent & Yes \\
\hline $\begin{array}{l}\text { Aluminum Tri- } \\
\text { dibutylphosphate }\end{array}$ & $\mathrm{AlC}_{24} \mathrm{H}_{54} \mathrm{O}_{12} \mathrm{P}_{3}$ & Possible Degradation Product & No \\
\hline Iron Tridibutylphosphate & $\mathrm{FeC}_{24} \mathrm{H}_{54} \mathrm{O}_{12} \mathrm{P}_{3}$ & Possible Degradation Product & No \\
\hline Sodium Dibutylphosphate & $\mathrm{NaC}_{8} \mathrm{H}_{18} \mathrm{O}_{4} \mathrm{P}$ & Possible Degradation Product & Yes \\
\hline Aluminum Oxalate & $\mathrm{Al}_{2} \mathrm{C}_{6} \mathrm{O}_{12} \cdot \times \mathrm{H}_{2} \mathrm{O}$ & Possible Degradation Product & No \\
\hline $\begin{array}{l}\text { Sodium Bis(2-ethylhexyl) } \\
\text { Phosphate }\end{array}$ & $\mathrm{NaC}_{16} \mathrm{H}_{34} \mathrm{O}_{4} \mathrm{P}$ & Process Reagent & Yes \\
\hline
\end{tabular}

The solubilitiy of the sodium salt of acetic acid in sodium hydroxide solutions and in pure water, respectively, have been reported. These solubility data were used as starting points for 
designing the solubility measurements. The available literature data (Morgan and Walker 1945) indicate that sodium acetate is very soluble in water and in sodium hydroxide solutions with hydroxide concentrations below $5 \mathrm{M}$. The solid phase of sodium acetate in equilibrium with these solutions is the hydrate, $\mathrm{NaC}_{2} \mathrm{H}_{3} \mathrm{O}_{2} \bullet 3 \mathrm{H}_{2} \mathrm{O}$.

In addition to the solubility measurements, adsorption of EDTA on simulated waste sludge solids was measured. The objective of these tests was to determine if dissolved EDTA in simulated supernate solution will react with HLW sludge metal ions to form insoluble precipitates or to adsorb onto surfaces of precipitated hydrous oxides in the sludges. The measurements covered a range of sodium hydroxide concentrations, tetrasodium ethylenediaminetetraacetate concentrations and metal ions.

\subsection{EXPERIMENTAL}

\subsection{Materials And Equipment}

All starting chemicals used in these measurements were reagent grade. All solutions were prepared using purified, deionized water. Mixtures of solid sodium salts of the organic acids, sodium nitrate, and solutions of sodium nitrate, sodium nitrite, and sodium hydroxide were continuously equilibrated in a water shaker bath (Precision Scientific Model 50) with a constant temperature accuracy of $\pm 0.1{ }^{\circ} \mathrm{C}$. The mixtures were contained in $50 \mathrm{~mL}$ polypropylene centrifuge tubes with screw caps so that an airtight seal could be maintained during equilibrium. Mechanical shaking of the mixtures shortened the equilibration times. Initially, the solutions were either saturated with crystalline sodium nitrate or the concentration of sodium nitrate was adjusted to $4.0 \mathrm{M}$ and the initial sodium nitrite concentration was either $2.0 \mathrm{M}$ or $0.97 \mathrm{M}$. Initial sodium hydroxide concentrations varied from $0.0003 \mathrm{M}$ to $2.0 \mathrm{M}$.

\subsection{Analyses}

Measurements of concentrations of sodium salts of acetate, glycolate, formate, oxalate, nitrate and nitrite were performed using liquid chromatography. A Dionex** Model DX-500 liquid chromatograph with a conductivity detector was used for these analyses. Standard solutions for calibration of the chromatograph were prepared from reagent sodium nitrate, sodium nitrite and the sodium salt of the organic acid dried at $110^{\circ} \mathrm{C}$. Standards were run before and after each set of analyses. The observed errors in the analyses of the standards were generally less than $5 \%$ relative error.

Sodium EDTA, NTA, and citrate concentrations (when only one organic salt was present in the equilibrated mixture) were determined by measuring the dissolved TOC using a Dohrmann DC-180 total organic carbon analyzer (Dohrmann, Santa Clara, California). This analyzer was used in the NPOC or non-purgeable organic carbon mode in which inorganic carbon was removed from solution by adding acid and the resulting solution was sparged with oxygen gas before analysis of the organic. The EDTA, NTA, and citrate TOC was analyzed by oxidizing it to

\footnotetext{
**Dionex is a registered trademark of Dionex Corporation, Sunnyvale California.
} 
carbon dioxide and then measuring the amount of carbon dioxide produced. Standard solutions of EDTA, NTA, and citrate were prepared from the dried reagent grade acids. The instrument was calibrated with these solutions and with a standard solution of potassium hydrogen pthalate. Each calibration standard and sample was analyzed four times and the relative standard deviations ranged from about $4 \%$ at $4 \mathrm{ppmC}$ to $1 \%$ at $56 \mathrm{ppmC}$.

Solution samples from the complex waste simulant tests were analyzed for sodium EDTA, NTA, citrate, glycolate, nitrate, and nitrite by the Pacific Northwest National Laboratory.

\subsection{Methods}

Solubilities were determined by measuring concentrations of organics in the aqueous phase of simulated HLW waste mixtures equilibrated at a constant temperature. Solubilities were measured at $25^{\circ} \mathrm{C}, 30^{\circ} \mathrm{C}, 40^{\circ} \mathrm{C}$, and $50^{\circ} \mathrm{C}$. The sodium salt of the organic compound being tested was always present as a crystalline solid during the measurements to ensure saturation of the aqueous solution. For measurements using simulated supernate solutions saturated with sodium nitrate, crystalline sodium nitrate was also always present. The procedure used for conducting the solubility measurements addressed the following four requirements for solubility determination:

1. The temperature of the equilibrating mixtures must be maintained at a constant value.

2. The attainment of equilibrium in the mixtures before sampling the phases must be proven.

3. Sampling the liquid and solid phases must be accomplished without affecting the composition of the phases.

4. The liquid and solid phases must be analyzed to determine their composition and the crystalline identity of the solids.

To determine whether equilibrium had been reached at a given temperature, equilibrium was approached from undersaturation and supersaturation. Also, changes in organic concentrations in the aqueous phases were monitored over time. Solubility equilibrium was achieved if the organic concentrations remained constant over time and the solubilities from undersaturation and supersaturation were the same. Measurements from undersaturation were performed by equilibrating mixtures at the lowest temperature $\left(25^{\circ} \mathrm{C}\right)$, measuring organic concentrations over time, and then repeating the equilibration at increasing temperature steps of $30^{\circ} \mathrm{C}, 40^{\circ} \mathrm{C}$, and 50 ${ }^{\circ} \mathrm{C}$. Equilibration from supersaturated solutions was accomplished by heating the mixtures at 60 ${ }^{\circ} \mathrm{C}$ for two days, cooling and equilibrating at $50^{\circ} \mathrm{C}$, and then repeating the equilibrations at decreasing temperature steps of $40^{\circ} \mathrm{C}, 30^{\circ} \mathrm{C}$, and $25^{\circ} \mathrm{C}$.

Required equilibration times were determined by sampling a given solution periodically until a constant concentration of dissolved organic was observed. Samples of the equilibrated mixtures were removed from the centrifuge tubes and placed in $5-\mathrm{mL}$ syringes fitted with syringe filters $(0.45 \mu \mathrm{m}$, polytetrafluoroethylene). The syringe, filter, and a vial used to receive the filtrate were pre-equilibrated at the sample temperature to prevent crystallization or dissolution during filtration. Approximately $2 \mathrm{mLs}$ of the mixture were filtered through the syringe filter. Exactly 
$1.000 \mathrm{~mL}$ of the filtrate was diluted with $10.00 \mathrm{mLs}$ of deionized water to prevent crystallization. These diluted samples were then analyzed by ion chromatography or by TOC analysis.

Solubilities of the organic salts in synthetic supernate solutions saturated with sodium nitrate were measured by preparing a series of solutions containing $2.0 \mathrm{M} \mathrm{NaNO}_{3}$ and various concentrations of sodium hydroxide $(0.1 \mathrm{M}, 0.5 \mathrm{M}, 1.0 \mathrm{M}$, and $2.0 \mathrm{M})$. Enough of the organic sodium salt and sodium nitrate was added to the solution to saturate it at $60^{\circ} \mathrm{C}$. The mixtures were cooled to $50^{\circ} \mathrm{C}$ and equilibrated for three weeks, sampling the solutions after each week. The equilibration and sampling was repeated at decreasing temperature steps of $40^{\circ} \mathrm{C}, 30^{\circ} \mathrm{C}$, and $25^{\circ} \mathrm{C}$.

Solubilities of sodium EDTA, NTA, citrate, and glycolate in two complex simulated waste mixtures were measured by adding sodium EDTA, NTA, citrate, glycolate, nitrate, carbonate, sulfate, and phosphate to deionized water in amounts that exceeded their solubilities. Solutions of nitrate salts of $\mathrm{Al}(\mathrm{III}), \mathrm{Fe}(\mathrm{III}), \mathrm{Cr}(\mathrm{III}), \mathrm{Bi}(\mathrm{III}), \mathrm{Ca}(\mathrm{II}), \mathrm{Ni}(\mathrm{II})$, and $\mathrm{Zr}(\mathrm{IV})$ were added to the above mixtures in addition to two different concentrations of sodium hydroxide to precipitate a simulated waste sludge as hydrous oxides. The final hydroxide concentrations were calculated to be $0.1 \mathrm{M}$ and $2.0 \mathrm{M}$. Equilibration and sampling of these solutions were the same as that described in the previous paragraph.

Adsorption of EDTA on precipitated metal hydrous oxide was measured by equilibrating simulated supernate solutions containing dissolved EDTA with precipitated hydrous oxides of $\mathrm{Al}(\mathrm{III}), \mathrm{Fe}(\mathrm{III}), \mathrm{Cr}$ (III), $\mathrm{Bi}$ (III), $\mathrm{Ca}$ (II), $\mathrm{Ni}(\mathrm{II})$, and $\mathrm{Zr}$ (IV). The solutions contained $4.0 \mathrm{M}$ $\mathrm{NaNO}_{3}$, and a range of sodium hydroxide concentrations $(0.001 \mathrm{M}, 0.010 \mathrm{M}, 0.10 \mathrm{M}, 0.50 \mathrm{M}$, and $1.0 \mathrm{M})$ and tetrasodium EDTA concentrations $(0.10 \mathrm{M}, 0.010 \mathrm{M}$, and $0.001 \mathrm{M})$. These mixtures, along with blank solutions containing no hydrous oxide, were equilibrated in centrifuge tubes at $25^{\circ} \mathrm{C}$ for 5 to 11 days in a shaker-water bath. The mixtures were then centrifuged and sampled for EDTA analysis.

\subsection{RESULTS AND DISCUSSION}

\subsection{Solution Densities}

The densities of solutions saturated with the organic salts were measured at $25^{\circ} \mathrm{C}, 30^{\circ} \mathrm{C}, 40$ ${ }^{\circ} \mathrm{C}$ and $50^{\circ} \mathrm{C}$ so that concentrations in molalities or weight percent could be calculated from the molar concentrations given in this study. Densities of sodium acetate solutions were not measurably different over this temperature range. The solution densities are also an indication of the concentrations of the sodium salts in solution because the salts are more dense than water. Table 3-1 compares densities of the $4.0 \mathrm{M} \mathrm{NaNO}_{3}-0.97 \mathrm{M} \mathrm{NaNO}_{2}$ simulant solution with average densities of saturated solutions of the actetate salt over the temperature range studied. Densities of solutions saturated with sodium acetate are only slightly higher than the simulant solution and reflect the low density of this salt. 
Table 3-1. Densities of the simulated supernate solutions and supernate solutions saturated with sodium acetate at $25^{\circ} \mathrm{C}$ to $50^{\circ} \mathrm{C}$.

\begin{tabular}{lcc}
\hline Initial & \multicolumn{2}{c}{ Densities of Saturated Solutions, g/.mL } \\
\cline { 2 - 3 }$[\mathrm{NaOH}], \mathrm{M}$ & Simulant & Acetate \\
\hline 0.00003 & 1.250 & 1.252 \\
0.001 & 1.255 & 1.277 \\
0.01 & 1.244 & 1.254 \\
0.1 & 1.253 & 1.288 \\
0.5 & 1.258 & 1.284 \\
1.0 & 1.286 & 1.271 \\
2.0 & 1.320 & 1.316 \\
\hline
\end{tabular}

Solution densities were also measured for supernates saturated with both the organic salts and crystalline sodium nitrate at $25^{\circ} \mathrm{C}, 30^{\circ} \mathrm{C}, 40^{\circ} \mathrm{C}$ and $50^{\circ} \mathrm{C}$ over a range of initial sodium hydroxide concentrations $(0.1 \mathrm{M}$ to $2.0 \mathrm{M})$. These data are presented in the previous progress report (Barney, 1996).

Densities of the complex simulated waste solutions were $1.510 \mathrm{~g} / \mathrm{mL}$ and $1.510 \mathrm{~g} / \mathrm{mL}$ at $40^{\circ} \mathrm{C}$, and $1.532 \mathrm{~g} / \mathrm{mL}$ and $1.473 \mathrm{~g} / \mathrm{mL}$ at $50^{\circ} \mathrm{C}$ for solutions containing $0.3 \mathrm{M}$ and $6.0 \mathrm{M}$ hydroxide, respectively.

\subsection{Evidence For Equilibrium}

Evidence for attainment of dissolution/crystallization equilibrium was obtained at each of the four temperatures studied. As described in the Methods section, solubilities of sodium acetate were measured from undersaturation and supersaturation. The temperature was held constant over a period of time to allow equilibration. Because the time required for equilibration was unknown, samples of the aqueous phases were taken periodically to monitor changes in organic concentrations. Average concentrations of acetate over all the seven initial sodium hydroxide concentrations at $25^{\circ} \mathrm{C}, 30^{\circ} \mathrm{C}, 40^{\circ} \mathrm{C}$, and $50^{\circ} \mathrm{C}$ are shown in Table $3-2$ so that an overall trend of dissolution or crystallization could be observed. .

The data from undersaturation measurements clearly show that acetate concentrations were not constant over the 21-day period, but generally increased over time. Comparison of values from supersaturation were higher than from undersaturation. The data clearly show that equilibrium was not reached from undersaturation over 21 days of equilibration. From supersaturation, equilibrium was attained rapidly for sodium acetate. The equilibrium solubility values reported here for acetate are averages of those obtained from supersaturation.

Prior measurements (Barney 1994, 1995, and 1996) have shown that attainment of equilibrium is generally faster from supersaturation. For this reason all of the solubility measurements of organics in saturated sodium nitrate solutions were obtained with equilibrium being reached from supersaturation. The concentrations of the organic salts in solution over the 21-day equilibration period for each temperature were essentially constant. This proves that the reported values are equilibrium solubilities. 
Table 3-2. Average concentrations of acetate versus time over all sodium hydroxide concentrations.

\begin{tabular}{|c|c|c|c|c|}
\hline $\begin{array}{l}\text { Equilibration } \\
\text { Time, Days }\end{array}$ & \multicolumn{4}{|c|}{ Average [Acetate], $\mathrm{M}$} \\
\hline \multicolumn{5}{|l|}{ From } \\
\hline Undersaturation & $25^{\circ} \mathrm{C}$ & $30^{\circ} \mathrm{C}$ & $40^{\circ} \mathrm{C}$ & $50^{\circ} \mathrm{C}$ \\
\hline 7 & 3.77 & 4.34 & 5.77 & 7.74 \\
\hline 14 & 3.99 & 4.35 & 5.77 & 7.68 \\
\hline 21 & 4.02 & 4.93 & 5.97 & 7.67 \\
\hline \multicolumn{5}{|l|}{ From } \\
\hline Supersaturation & & & & \\
\hline 7 & 4.91 & 5.30 & 6.17 & NA \\
\hline 14 & 4.87 & 5.24 & 6.25 & 7.99 \\
\hline 21 & 5.00 & 5.42 & 6.30 & 7.88 \\
\hline
\end{tabular}

*ND $=$ not determined.

\subsection{Solution Volume Increases}

Because of their high solubilities, dissolution of most sodium salts of organic acids in the simulant solutions resulted in significant volume increases in these solutions. This volume increase caused a corresponding dilution of the initial concentrations of sodium nitrate, nitrite, and hydroxide. For solutions saturated with sodium nitrate, the volume increases due to dissolution of this salt added to the total volume increase. The volume increases for sodium acetate solutions shown in Table 3-3 (for initial sodium hydroxide concentrations of $0.1 \underline{\mathrm{M}}$ ) were calculated from the change in concentration of nitrite after dissolution of the organics, according to the equation,

$\%$ Volume Increase $=100(1-$ Final Nitrite Concentration/Initial Nitrite Concentration $)$.

The volume increases for sodium acetate dissolution were larger than for sodium acetate + sodium nitrate dissolution because hydrated sodium acetate $\left(\mathrm{NaC}_{2} \mathrm{H}_{3} \mathrm{O}_{2} \cdot 3 \mathrm{H}_{2} \mathrm{O}\right)$ was used in the former measurements, whereas anhydrous sodium acetate was used in the latter measurements.

Table 3-3. Volume increases due to dissolution of sodium acetate and sodium acetate + sodium nitrate.

\begin{tabular}{lcccc} 
& \multicolumn{4}{c}{$\%$ Volume Increase } \\
\cline { 2 - 5 } Dissolved Salts & $50^{\circ} \mathrm{C}$ & $40^{\circ} \mathrm{C}$ & $30^{\circ} \mathrm{C}$ & $25^{\circ} \mathrm{C}$ \\
\hline Acetate & 75 & 69 & 68 & 65 \\
Acetate + Nitrate & 55 & 52 & 47 & 40 \\
\hline
\end{tabular}


HNF-EP-0899-2

\subsection{Sodium Acetate Solubility}

Sodium acetate is very soluble in simulated HLW supernate solutions. At low sodium hydroxide concentrations, acetate solubilities as high as $8.0 \mathrm{M}$ were observed. The temperature effect on solubility was relatively large compared to the other compounds studied thus far. Acetate solubility is much greater at $50^{\circ} \mathrm{C}$ than at $25^{\circ} \mathrm{C}$. Figure $3-1$ shows that the solubility decreased as sodium hydroxide concentration increased, probably because of the common ion effect of $\mathrm{Na}^{+}$. Literature data (Morgan and Walker 1945) show a strong effect of sodium hydroxide on sodium acetate solubility. At about 2.3 and $4.2 \mathrm{M} \mathrm{NaOH}$ (total sodium in the current test solutions, excluding that sodium from sodium acetate, is about 8-9 M) these literature data predict a solubility of about 3.6 and $2.4 \mathrm{M}$ sodium acetate. This is in rough agreement with the data presented in this document. Sodium acetate forms a crystalline hydrate, $\mathrm{NaC}_{2} \mathrm{H}_{3} \mathrm{O}_{2} \cdot 3 \mathrm{H}_{2} \mathrm{O}$, in equilibrium with the simulated waste solutions.

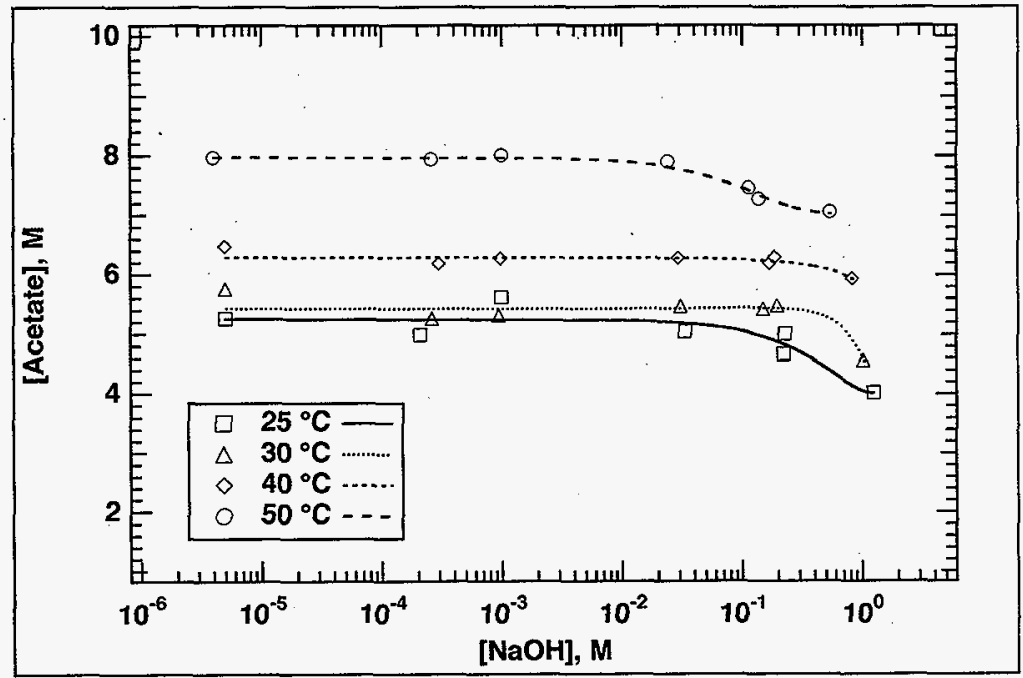

Figure 3-1. Solubility of sodium acetate in $\mathrm{NaNO}_{3}-\mathrm{NaNO}_{2}$ solutions at $25^{\circ} \mathrm{C}, 30^{\circ} \mathrm{C}, 40^{\circ} \mathrm{C}$, and $50^{\circ} \mathrm{C}$ for various sodium hydroxide concentrations.

Detailed solubility measurement data for the organic salts reported in this document are given in Appendix A.

Sodium acetate solubilities in supernate simulants that are saturated with crystalline sodium nitrate are lower than those given above, as expected due to higher concentrations of the common ion, sodium. Figure 3-2A shows solubilities ranging from about 3.8 to $5.4 \mathrm{M}$ sodium acetate, which is several molar units less than for solutions not fully saturated with sodium nitrate. The 
HNF-EP-0899-2

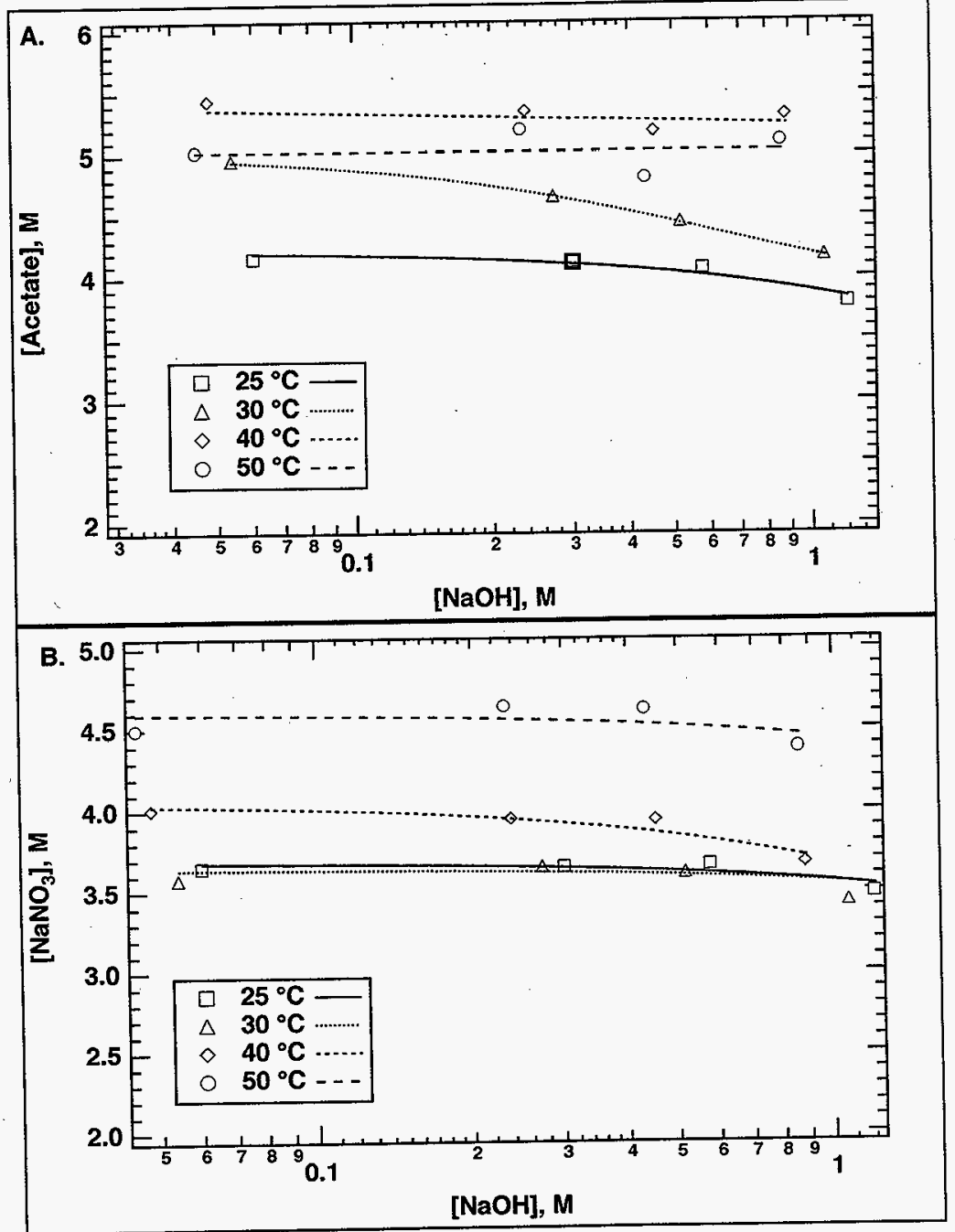

Figure 3-2. Solubility of sodium acetate in $\mathrm{NaNO}_{3}-\mathrm{NaNO}_{2}$ solutions saturated with crystalline $\mathrm{NaNO}_{3}$ at $25^{\circ} \mathrm{C}$, $30^{\circ} \mathrm{C}, 40^{\circ} \mathrm{C}$, and $50^{\circ} \mathrm{C}$ for various sodium hydroxide concentrations $(\mathrm{A})$, and measured sodium nitrate concentrations in the same solutions (B). 
HNF-EP-0899-2

acetate solubility is at a maximum at $40^{\circ} \mathrm{C}$ and decreases at $50^{\circ} \mathrm{C}$ due to the higher solubility of sodium nitrate at $50^{\circ} \mathrm{C}$ (Figure $3-2 \mathrm{~B}$ ). The solubilities of both sodium acetate and sodium nitrate are slightly depressed by increased sodium hydroxide concentrations.

\subsection{Sodium Glycolate Solubility}

Sodium glycolate was also quite soluble in the simulated HLW supernate solutions that were saturated with crystalline sodium nitrate. Sodium glycolate solubilities ranged from 3.6 to $4.2 \mathrm{M}$ over the temperatures and sodium hydroxide and sodium nitrite concentrations studied. As expected, the solubilities are less than those reported earlier $(4.4$ to $5.8 \mathrm{M})$ for solutions not saturated with sodium nitrate (Barney 1995). Figure 3-3A shows that solubilities decreased as the temperature was raised, especially at $50^{\circ} \mathrm{C}$. This is due to the common ion effect of sodium for solutions containing higher sodium nitrate concentrations. Solubilities slightly increased as sodium hydroxide concentrations increased. This behavior is not observed for any other organic salt studied and may be due to deprotonation of the $-\mathrm{OH}$ group on the glycolate molecule at high hydroxide concentrations.

Figure 3-3B shows that more sodium nitrate dissolved as the temperature of the mixtures increased. These increased sodium nitrate concentrations lowered glycolate solubilities due to the common ion effect of sodium. In contrast to glycolate solubilities, increased sodium hydroxide concentrations lowered the solubility of sodium nitrate.

\subsection{Sodium Citrate Solubility}

Sodium citrate was not as soluble as most other organic salts in the simulated HLW supernate solutions that were saturated with crystalline sodium nitrate. Sodium citrate solubilities ranged from 0.42 to $0.63 \mathrm{M}$ over the temperatures, sodium hydroxide concentrations, and sodium nitrite concentrations studied. As expected, the solubilities are less than those reported earlier $(0.65$ to $1.2 \mathrm{M}$ ) for solutions not saturated with sodium nitrate (Barney 1995). Figure 3-4A shows no clear trend in the change of solubilities as the temperature was raised, although a maximum solubility appears to be at about $40^{\circ} \mathrm{C}$. The lowering of the solubility at 0.3 $\mathrm{M} \mathrm{NaOH}$ at 25 and $30^{\circ} \mathrm{C}$ is reproduceable and may be due to a phase change of the sodium citrate salt under these conditions. Solubilities decreased as sodium hydroxide concentrations increased. This is a result of the common ion effect of sodium and solution ionic strength effects.

Figure $3-4 \mathrm{~B}$ shows that more sodium nitrate dissolved as the temperature of the mixtures increased. These increased sodium nitrate concentrations lowered citrate solubilities due to the common ion effect of sodium. Increased sodium hydroxide concentrations lowered the solubility of sodium nitrate. 


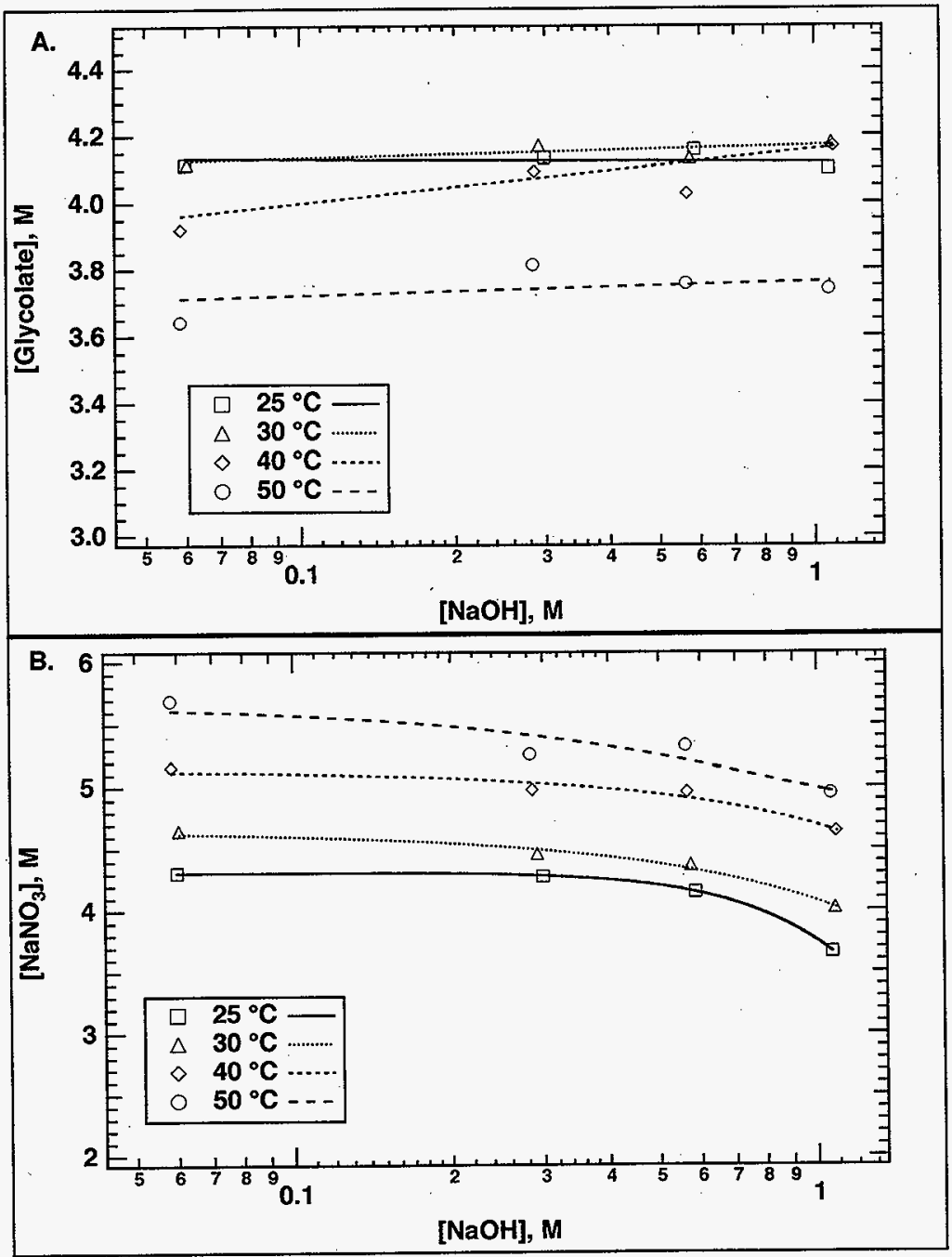

Figure 3-3. Solubility of sodium glycolate in $\mathrm{NaNO}_{3}-\mathrm{NaNO}_{2}$ solutions saturated with crystalline $\mathrm{NaNO}_{3}$ at 25 ${ }^{\circ} \mathrm{C}, 30^{\circ} \mathrm{C}, 40^{\circ} \mathrm{C}$, and $50^{\circ} \mathrm{C}$ for various sodium hydroxide concentrations (A), and measured sodium nitrate concentrations in the same solutions $(B)$. 


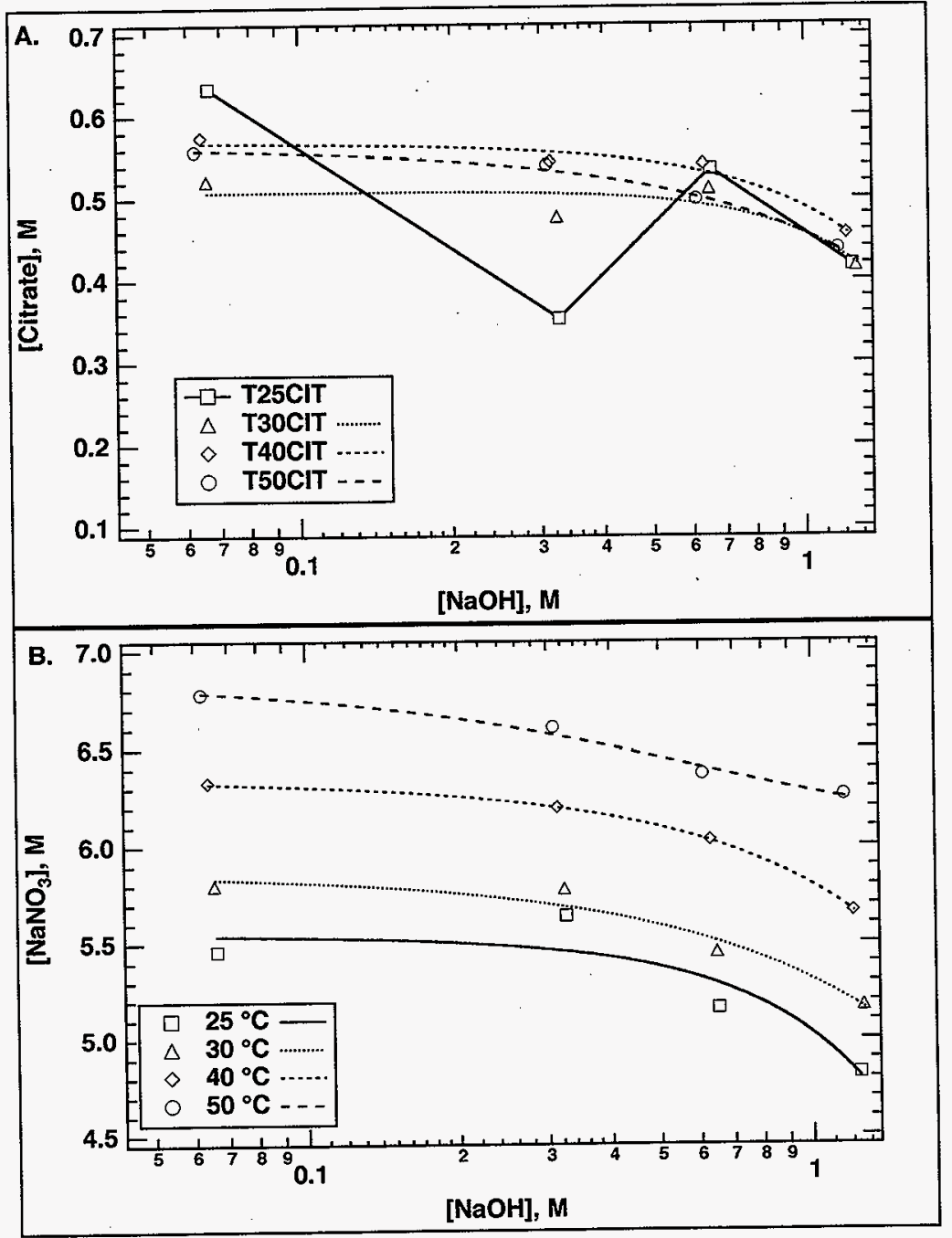

Figure 3-4. Solubility of sodium citrate in $\mathrm{NaNO}_{3}-\mathrm{NaNO}_{2}$ solutions saturated with crystalline $\mathrm{NaNO}_{3}$ at $25^{\circ} \mathrm{C}$, $30^{\circ} \mathrm{C}, 40^{\circ} \mathrm{C}$, and $50^{\circ} \mathrm{C}$ for various sodium hydroxide concentrations (A), and measured sodium nitrate concentrations in the same solutions $(B)$. 


\subsection{Sodium EDTA Solubility}

Sodium EDTA was quite soluble in the simulated HLW supernate solutions that were saturated with crystalline sodium nitrate. Sodium EDTA solubilities ranged from 0.83 to $1.0 \mathrm{M}$ over the temperatures, sodium hydroxide concentrations, and sodium nitrite concentrations studied. As expected, the solubilities are generally less than those reported earlier $(0.65$ to 1.4 M) for solutions not saturated with sodium nitrate (Barney 1995). Figure 3-5A shows increasing solubilities as the temperature was raised up to $40^{\circ} \mathrm{C}$ and a dramatic lowering of the solubilities at $50^{\circ} \mathrm{C}$. Solubilities decreased as sodium hydroxide concentrations increased. This is a result of the common ion effect of sodium and solution ionic strength effects.

Figure 3-5B shows that more sodium nitrate dissolved as the temperature of the mixtures increased. These increased sodium nitrate concentrations lowered EDTA solubilities at $50^{\circ} \mathrm{C}$ due to the common ion effect of sodium. Increased sodium hydroxide concentrations lowered the solubility of sodium nitrate.

\subsection{Sodium NTA Solubility}

Sodium NTA was quite soluble in the simulated HLW supernate solutions that were saturated with crystalline sodium nitrate. Sodium NTA solubilities ranged from 0.81 to $1.2 \mathrm{M}$ over the temperatures, sodium hydroxide concentrations, and sodium nitrite concentrations studied. As expected, the solubilities are generally less than those reported earlier $(1.2$ to $1.8 \mathrm{M})$ for solutions not saturated with sodium nitrate (Barney 1995). Figure 3-6A shows decreasing solubilities as the temperature was raised from $25^{\circ} \mathrm{C}$ to $50^{\circ} \mathrm{C}$. Solubilities decreased as sodium hydroxide concentrations increased. This is a result of the common ion effect of sodium and solution ionic strength effects.

Figure 3-6B shows that more sodium nitrate dissolved as the temperature of the mixtures increased. These increased sodium nitrate concentrations lowered NTA solubilities due to the common ion effect of sodium. Increased sodium hydroxide concentrations lowered the solubility of sodium nitrate.

\subsection{Sodium Formate Solubility}

Sodium formate was quite soluble in the simulated HLW supernate solutions that were saturated with crystalline sodium nitrate. Sodium formate solubilities ranged from 6.6 to $8.5 \mathrm{M}$ over the temperatures, sodium hydroxide concentrations, and sodium nitrite concentrations studied. As expected, the solubilities are less than those reported earlier $(6.8$ to $9.8 \mathrm{M})$ for solutions not saturated with sodium nitrate (Barney 1995). Figure 3-7A shows decreasing solubilities as the temperature was raised from $25^{\circ} \mathrm{C}$ to $50^{\circ} \mathrm{C}$. Solubilities decreased as sodium hydroxide concentrations increased. This is a result of the common ion effect of sodium and solution ionic strength effects.

Figure 3-7B shows that more sodium nitrate generally dissolved as the temperature of the mixtures increased. These increased sodium nitrate concentrations lowered formate solubilities 


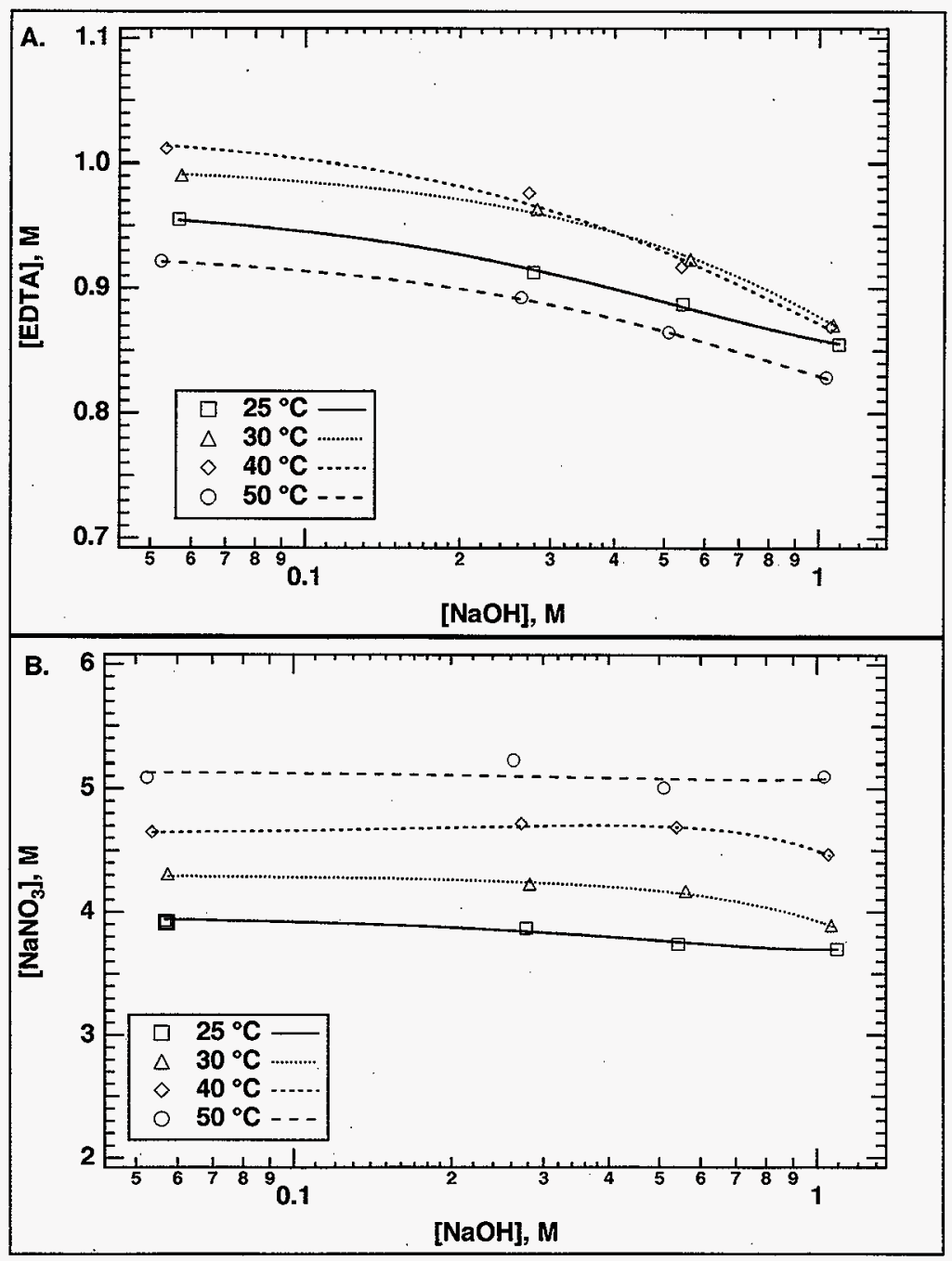

Figure 3-5. Solubility of sodium EDTA in $\mathrm{NaNO}_{3}-\mathrm{NaNO}_{2}$ solutions saturated with crystalline $\mathrm{NaNO}_{3}$ at $25^{\circ} \mathrm{C}$, $30^{\circ} \mathrm{C}, 40^{\circ} \mathrm{C}$, and $50^{\circ} \mathrm{C}$ for various sodium hydroxide concentrations $(\mathrm{A})$, and measured sodium nitrate concentrations in the same solutions (B). 
HNF-EP-0899-2

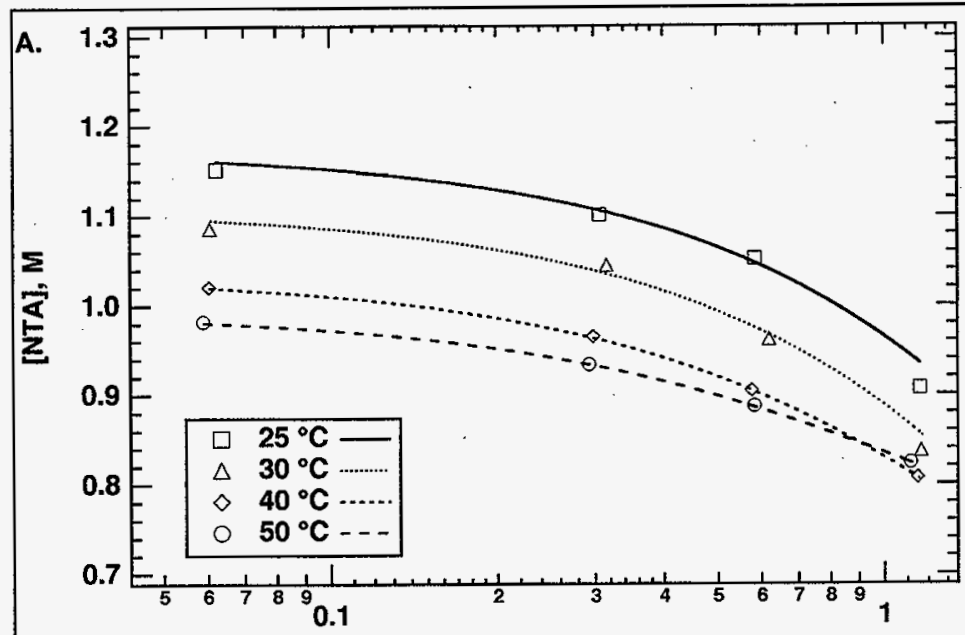

[NaOH], $\mathrm{M}$

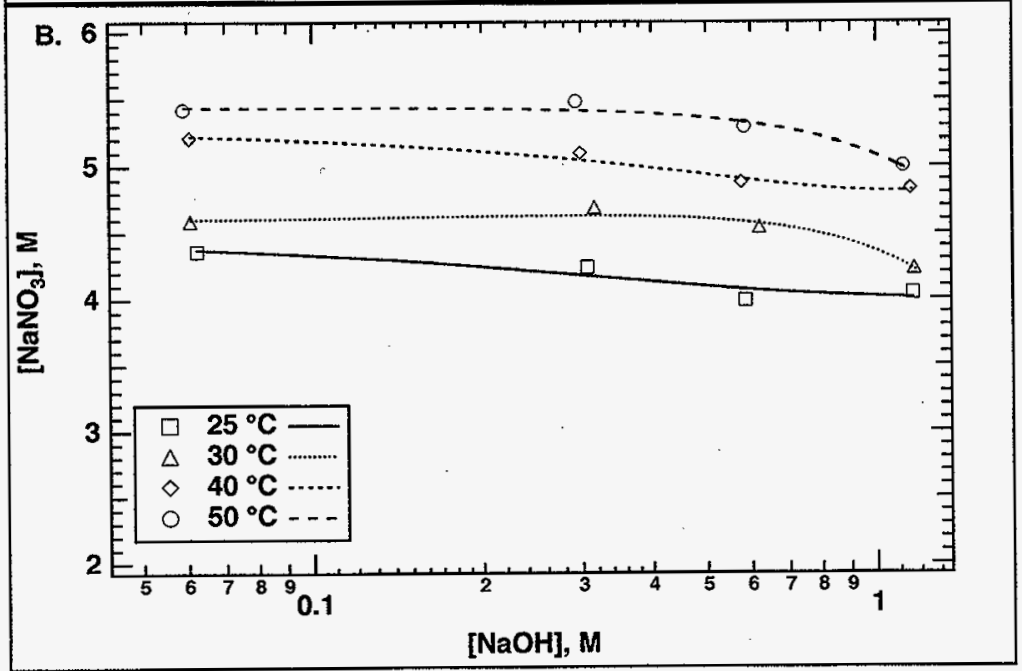

Figure 3-6. Solubility of sodium NTA in $\mathrm{NaNO}_{3}-\mathrm{NaNO}_{2}$ solutions saturated with crystalline $\mathrm{NaNO}_{3}$ at $25^{\circ} \mathrm{C}$, $30^{\circ} \mathrm{C}, 40^{\circ} \mathrm{C}$, and $50^{\circ} \mathrm{C}$ for various sodium hydroxide concentrations $(\mathrm{A})$, and measured sodium nitrate concentrations in the same solutions (B). 


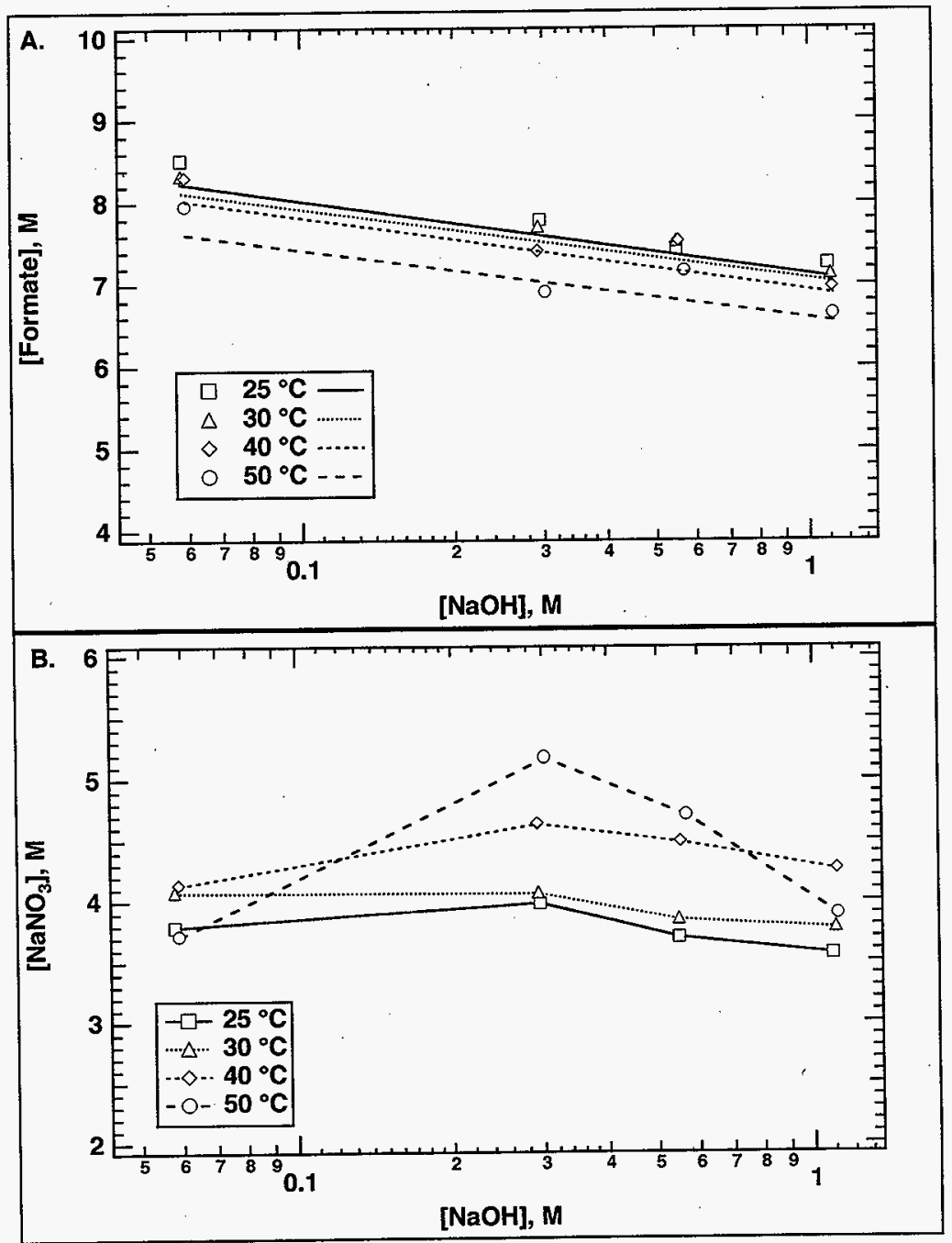

Figure 3-7. Solubility of sodium formate in $\mathrm{NaNO}_{3}-\mathrm{NaNO}_{2}$ solutions saturated with crystalline $\mathrm{NaNO}_{3}$ at $25^{\circ} \mathrm{C}$, $30^{\circ} \mathrm{C}, 40^{\circ} \mathrm{C}$, and $50^{\circ} \mathrm{C}$ for various sodium hydroxide concentrations (A), and measured sodium nitrate concentrations in the same solutions (B). 


\section{HNF-EP-0899-2}

due to the common ion effect of sodium. Increased sodium hydroxide concentrations lowered the solubility of sodium nitrate.

\subsection{Sodium Oxalate Solubility}

Sodium oxalate was only slightly soluble in the simulated HLW supernate solutions that were saturated with crystalline sodium nitrate. Sodium oxalate solubilities ranged from 0.0012 to $0.0039 \mathrm{M}$ over the temperatures, sodium hydroxide concentrations, and sodium nitrite concentrations studied. As expected, the solubilities are generally less than those reported earlier $(0.0036$ to $0.015 \mathrm{M})$ for solutions not saturated with sodium nitrate (Barney 1995). Figure 3-8A shows no clear trend in solubilities as the temperature was raised from $25^{\circ} \mathrm{C}$ to $50^{\circ} \mathrm{C}$. The maximum solubilities measured were at $30^{\circ} \mathrm{C}$. Solubilities increased as sodium hydroxide concentrations increased. This is a result of the common ion effect of sodium from sodium nitrate dissolution and solution ionic strength effects.

Figure 3-8B shows that more sodium nitrate dissolved as the temperature of the mixtures incereased. These increased sodium nitrate concentrations had no obvious effect on oxalate solubilities. Increased sodium hydroxide concentrations lowered the solubility of sodium nitrate.

\subsection{EDTA Adsorption on Metal Hydrous Oxides}

Adsorption dissolved organics on waste solids or precipitation as insoluble complexes of metal ions (other than sodium) in the wastes are additional mechanisms that can potentially remove organic compounds from solution and deposit them in the solid phases of HLW tank waste. Adsorption of complexants, such as EDTA and metal ion complexes of EDTA, from aqueous solutions onto metal oxide surfaces has been observed in a number of studies (Nowack et al. 1996; Bowers and Huang 1987; Nowack and Sigg 1996 and 1997; Blesa et al. 1984; and Chang and Matijevic 1983). Adsorption depends greatly on the $\mathrm{pH}$ of the solution, the temperature, the type of complexant, and the nature of the oxide surface. The solid phases in tank waste that could adsorb or precipitate organics are present in sludge layer as hydrous oxides of iron, aluminum, bismuth, calcium, chromium, nickel, silica, zirconium, and other minor metals. The salt cake phases, such as sodium nitrate, phosphate, carbonate, sulfate, etc. are not likely to adsorb organic compounds from solution.

A series of experiments were completed to determine whether or not organics in the wastes can form insoluble complexes or compounds with heavy metal ions (iron, aluminum, bismuth, zirconium, etc.) present in the wastes. In addition, these experiments measured the extent of adsorption of organics on the surfaces of hydrous metal oxides that are present as sludges in the waste tanks. This work complements the organic solubility measurements which have shown that most sodium salts of the organics are very soluble in the supernate solutions. If there is little precipitation or adsorption of organies from the supernate by interaction with the heavy metal ions, then the organics will stay in solution where they cannot react dangerously with nitrate or nitrite. In these experiments, low concentrations of tetrasodium EDTA in $4.0 \mathrm{M}$ sodium nitrate solutions were contacted with precipitated ferric hydroxide, chromic hydroxide, and nickel hydroxide over various time periods. Any precipitation or adsorption of the EDTA was detected by a lowering of the EDTA concentration compared to the initial concentration. 


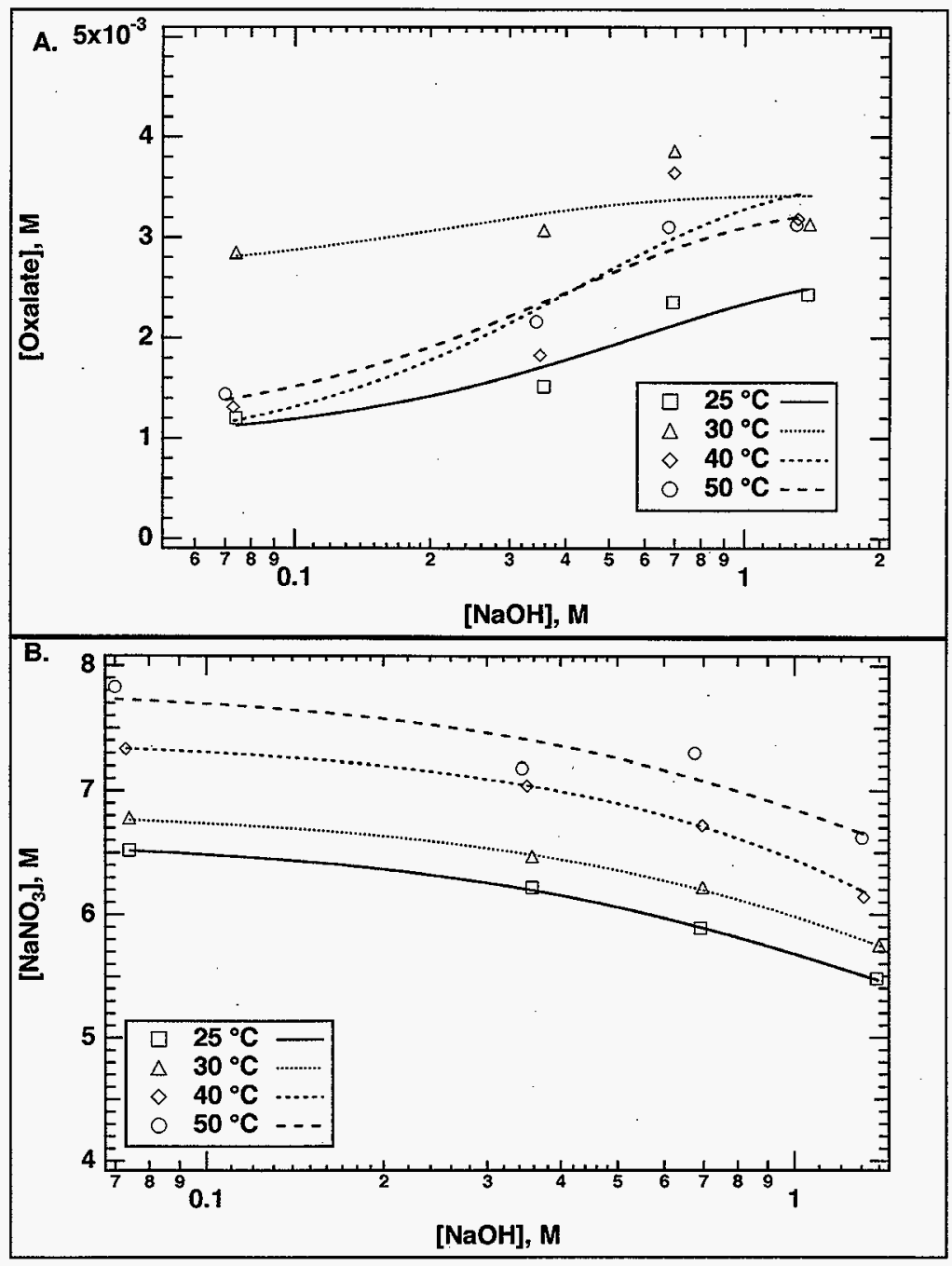

Figure 3-8. Solubility of sodium oxalate in $\mathrm{NaNO}_{3}-\mathrm{NaNO}_{2}$ solutions saturated with crystalline $\mathrm{NaNO}_{3}$ at $25^{\circ} \mathrm{C}$, $30^{\circ} \mathrm{C}, 40^{\circ} \mathrm{C}$, and $50^{\circ} \mathrm{C}$ for various sodium hydroxide concentrations $(\mathrm{A})$, and measured sodium nitrate concentrations in the same solutions (B). 
The variables investigated were sodium hydroxide concentration, EDTA concentration, and time. EDTA was used as a surrogate complexant because of its ability to form very strong complexes with metal ions. If EDTA showed little interaction with metal hydrous oxides, then other complexants are not likely to interact either.

The experiments covered a range of sodium hydroxide concentrations, EDTA concentrations, and metal ions. Metal ions included in the experiments are $\mathrm{Fe}^{3+}, \mathrm{Cr}^{3+}, \mathrm{Ca}^{2+}$, and $\mathrm{Ni}^{2+}$. The solutions all contained $4.0 \mathrm{M}$ sodium nitrate to simulate waste supernate solutions. The results showed that complexants in the wastes may very well be complexed by metal ions in the waste. Tests using simulated waste solutions over a wide range of EDTA concentrations and hydroxide concentrations show that some metal complexes of EDTA are stable and soluble even at high hydroxide concentrations. For example, $\mathrm{Ca}$ (II), $\mathrm{Ni}$ (II), and $\mathrm{Cr}$ (III) complexes of EDTA are stable and soluble even at $1.0 \mathrm{M} \mathrm{NaOH}$. This data appears to confirm that the EDTA will remain mostly in solution even if complexed with metal ions. Tests with iron hydrous oxide, show that a small amount of EDTA is removed from solution, probably by adsorption rather than by precipitation of an insoluble iron-EDTA complex. Figure 3-9 shows the percent of EDTA adsorbed onto precipitated ferric hydroxide over a range of initial EDTA concentrations and sodium hydroxide concentrations. Adsorption decreased as the hydroxide concentration increases, as would be expected for adsorption of anionic complexants. The greatest amount of EDTA adsorbed was about 0.02 mmoles EDTA/mmole Fe at $0.001 \mathrm{M} \mathrm{OH}$.

Adsorption of EDTA on precipitated chromic hydroxide was greater than for ferric hydroxide. Figure 3-10 shows that about 82 percent of initial EDTA is adsorbed onto chromic hydroxide. As for ferric hydroxide, adsorption increases as hydroxide concentration decreases. The greatest amount adsorbed was about 0.05 mmoles EDTA/mmole $\operatorname{Cr}$ at $0.001 \mathrm{M} \mathrm{OH}^{-}$.

Adsorption of EDTA on precipitated nickel hydroxide was the least extensive of the hydrous oxides studied. Figure 3-11 shows that a maximum of 46 percent of $0.001 \mathrm{M}$ EDTA was adsorbed at $0.01 \mathrm{M} \mathrm{OH}^{-}$. This corresponds to about $0.008 \mathrm{mmolesEDTA} / \mathrm{mmole}$ Ni. No precipitated nickel hydroxide was observed in the tests with $0.1 \mathrm{M}$ EDTA even at $1.0 \mathrm{M} \mathrm{NaOH}$. The nickel EDTA complex is stable and soluble even at high hydroxide concentrations.

These results show that ethylenediaminetraacetate (EDTA) or EDTA-metal complexes can be adsorbed onto hydrous metal oxides (that make up the sludge layers in the tanks) under conditions simulating the high-level waste tanks. The extent of adsorption is not large and depends on the concentration of hydroxide in the wastes solutions. Higher hydroxide concentrations lower adsorption of EDTA. Adsorption also depends on the type of metal hydrous oxide present. Adsorption data for $\mathrm{Fe}$ (III), $\mathrm{Cr}$ (III), and $\mathrm{Ni}$ (II) hydrous oxides show that chromium(III) hydrous oxide adsorbs EDTA most efficiently. 


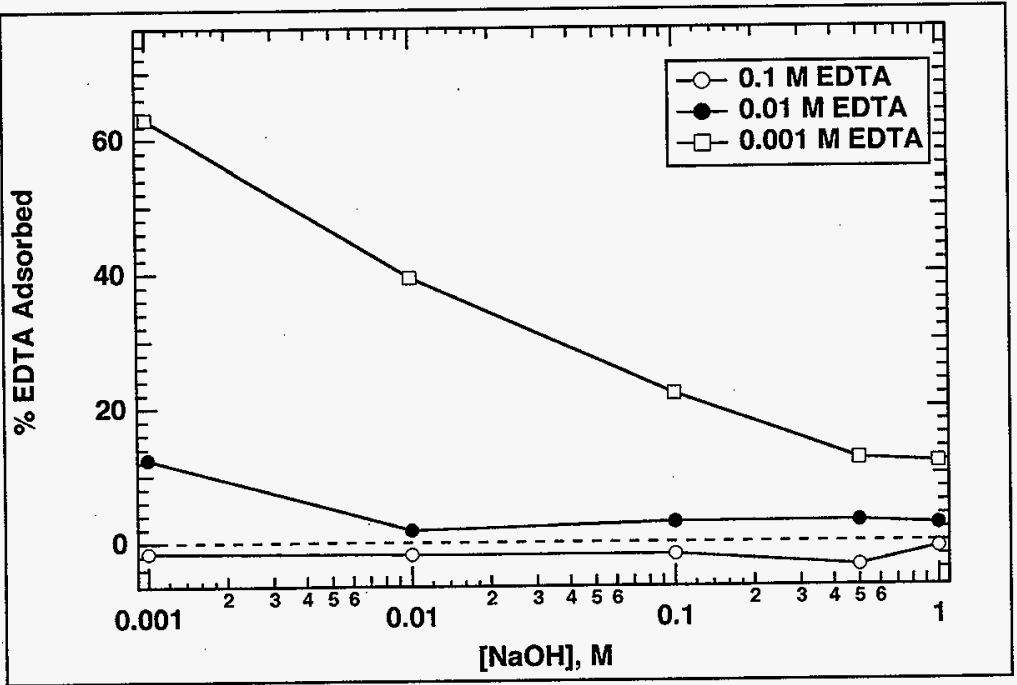

Figure 3-9. Adsorption of EDTA on precipitated ferric hydroxide in $4.2 \mathrm{M} \mathrm{NaNO}_{3}$ solutions at $25^{\circ} \mathrm{C}$ for various sodium hydroxide concentrations and initial tetrasodium EDTA concentrations of $0.1 \mathrm{M}, 0.01 \mathrm{M}$, and $0.001 \mathrm{M}$.(B). 
HNF-EP-0899-2

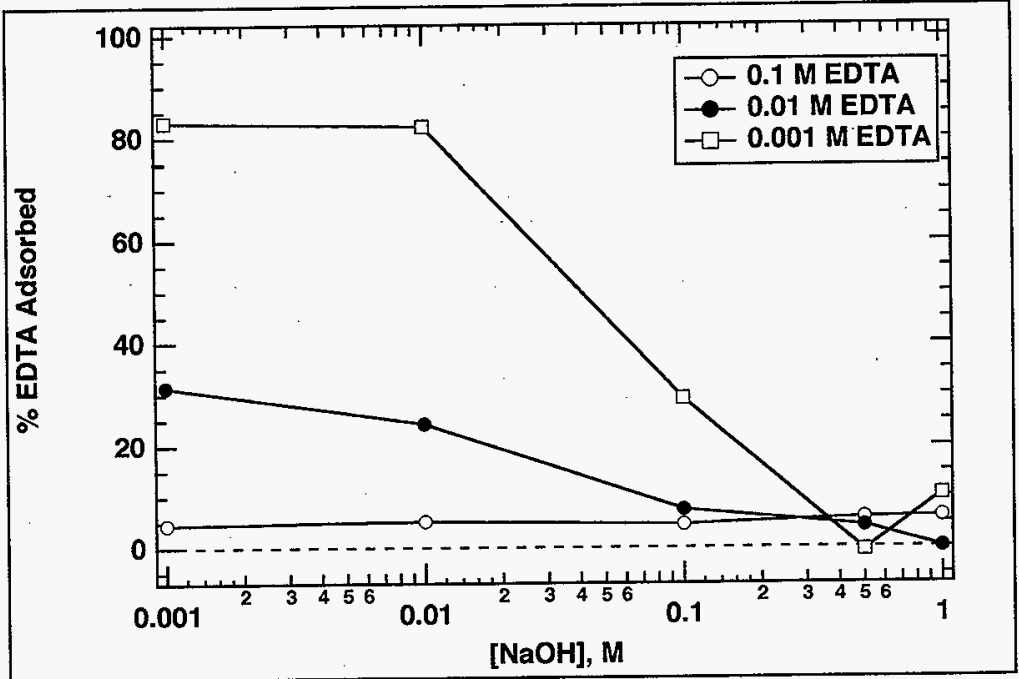

Figure 3-10. Adsorption of EDTA on precipitated chromic hydroxide in $4.2 \mathrm{M} \mathrm{NaNO}_{3}$ solutions at $25^{\circ} \mathrm{C}$ for various sodium hydroxide concentrations and initial tetrasodium EDTA concentrations of $0.1 \mathrm{M}, 0.01 \mathrm{M}$, and 0.001 M.(B). 


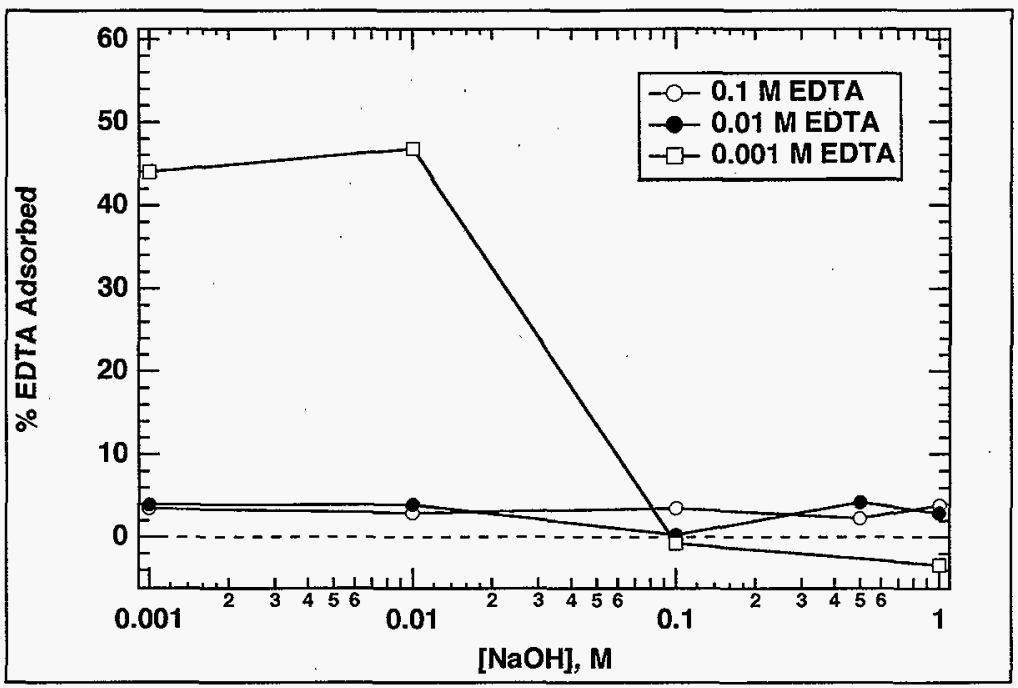

Figure 3-11. Adsorption of EDTA on precipitated nickel hydroxide in $4.2 \mathrm{M} \mathrm{NaNO} 3$ solutions at $25^{\circ} \mathrm{C}$ for various sodium hydroxide concentrations and initial tetrasodium EDTA concentrations of $0.1 \mathrm{M}, 0.01 \mathrm{M}$, and 0.001 M.(B).

\subsection{Solubilities in Complex Waste Mixtures}

Most of the organic solubility measurements performed for this project have been obtained using a simplified waste simulant consisting of an aqueous salt solution and solid organic salt (sometimes with crystalline sodium nitrate). Actual waste mixtures are, of course, more complex and contain other sodium salts, metal hydrous oxides, mixtures of organic salts, and other components. To determine the effects of these additional components on the solubilities of important organic salts, two complex mixtures were prepared containing 17 components known to exist in the wastes. The solubilities of sodium EDTA, citrate, glycolate, and NTA were measured at about 0.3 and $6.0 \mathrm{M} \mathrm{NaOH}$ in these mixtures.

The components of the waste mixtures are given in Table 3-4. The final molarities given in this table are those that would be present in solution if all the components completely dissolved in water with a final volume of $100 \mathrm{mLs}$. Most of the components are present in excess of their solubilities, so that the actual concentrations will be less. Only sodium nitrite and sodium hydroxide are unsaturated. The unsaturated components will be present in higher concentrations than shown in this table because the final volume of aqueous solution will be less than $100 \mathrm{mLs}$. Most of the volume was taken up by solids that saturated the solutions. Several of the metal nitrates reacted with sodium hydroxide to produce a hydrous oxide precipitate which simulates the presence of sludge waste. Nickel and calcium were likely complexed with the high 
concentrations of EDTA or NTA present. The blue color of the equilibrated aqueous solutions indicated the presence of the nickel complex.

Table 3-4. Components of simulated complex waste mixtures

\begin{tabular}{cc}
\hline Saturated Components & Final Molarity \\
\hline $\mathrm{Na}_{4} \mathrm{EDTA}$ & 0.4 \\
$\mathrm{Na}$ Citrate & 0.4 \\
$\mathrm{NaGlycolate}$ & 2.5 \\
$\mathrm{Na}_{3} \mathrm{NTA}^{2}$ & 0.6 \\
$\mathrm{NaNO}_{3}$ & 3 \\
$\mathrm{Na}_{2} \mathrm{CO}_{3}$ & 0.3 \\
$\mathrm{Na}_{2} \mathrm{SO}_{4}$ & 0.05 \\
$\mathrm{Na}_{3} \mathrm{PO}_{4}$ & 0.1 \\
$\mathrm{Al}\left(\mathrm{NO}_{3}\right)_{3}$ & 0.005 \\
$\mathrm{Fe}\left(\mathrm{NO}_{3}\right)_{3}$ & 0.005 \\
$\mathrm{Cr}\left(\mathrm{NO}_{3}\right)_{3}$ & 0.005 \\
$\mathrm{Bi}\left(\mathrm{NO}_{3}\right)_{3}$ & 0.005 \\
$\mathrm{Ca}\left(\mathrm{NO}_{3}\right)_{2}$ & 0.005 \\
$\mathrm{Ni}\left(\mathrm{NO}_{3}\right)_{2}$ & 0.005 \\
$\mathrm{ZrO}\left(\mathrm{NO}_{3}\right)_{2}$ & 0.005 \\
Unsaturated Components & \\
\hline $\mathrm{NaNO}$ & \\
$\mathrm{NaOH}$ & 1.0 \\
\hline
\end{tabular}

The equilibrium concentrations of dissolved components in the aqueous phase are shown in Table 3-5. The concentrations of sodium nitrite, assuming it all dissolved, show that there was only about $32 \mathrm{mLs}$ of aqueous solution at $40^{\circ} \mathrm{C}$ and $36 \mathrm{mLs}$ at $50^{\circ} \mathrm{C}$. This resulted in higher sodium hydroxide concentrations than expected. The solubilities of the organic salts are lower than those measured in simpler systems. This can be explained by the higher sodium concentrations and the higher sodium hydroxide concentrations in these complex mixtures. Table 3-6 shows average total sodium ion concentations for the different solution matrices used in making solubility measurements for sodium EDTA, citrate, glycolate, and NTA. The solutions saturated with sodium nitrate have total sodium ion concentrations of 0.4 to 2.5 molar higher than unsaturated solutions. The complex waste solutions have sodium ion concentrations 3.4 to 7.0 molar higher than unsaturated solutions. This causes a significant lowering of the solubilities of the organic sodium salts due to the common ion effect of sodium. This effect is shown in Figures 3-12, 3-13, 3-14 and 3-15 for sodium glycolate, citrate, EDTA, and NTA, respectively.

The solubility of glycolate actually increases with increasing sodium hydroxide concentration in the complex solutions. As discussed earlier this may be due to deprotonation of the $-\mathrm{OH}$ group on glycolate at these high hydroxide concentrations. The relatively low solubility of sodium NTA in the complex mixtures is probably due to high hydroxide concentrations (and high sodium ion concentrations). The solubility of sodium NTA is sensitive to hydroxide concentrations.

It should be stressed that the sodium ion concentrations in these complex mixtures are higher than would be expected for actual waste solutions. The sodium ion contribution from the sodium organic salts is very high and would not be present in actual waste solutions. For this reason, the solubilities of the organics in actual waste will be higher than measured here. 
Table 3-5. Equilibrium concentrations of complex waste mixture components.

\begin{tabular}{ccc:cc}
\hline & \multicolumn{2}{c}{$40^{\circ} \mathrm{C}$} & \multicolumn{2}{c}{$50{ }^{\circ} \mathrm{C}$} \\
\hline Component & $0.1 \mathrm{M} \mathrm{NaOH}$ & $2.0 \mathrm{M} \mathrm{NaOH}$ & $0.1 \mathrm{M} \mathrm{NaOH}$ & $2.0 \mathrm{M} \mathrm{NaOH}$ \\
\hline NaAEDTA & 0.52 & 0.36 & 0.54 & 0.38 \\
Nas Citrate & 0.19 & 0.15 & 0.17 & 0.15 \\
$\mathrm{NaGlycolate}$ & 2.26 & 2.53 & 1.97 & 2.34 \\
$\mathrm{Na}_{3} \mathrm{NTA}$ & 0.32 & 0.08 & 0.33 & 0.06 \\
$\mathrm{NaNO}_{3}$ & 3.03 & 3.47 & 2.53 & 3.20 \\
$\mathrm{NaNO}_{2}$ & 3.03 & 3.08 & 2.58 & 2.91 \\
$\mathrm{NaOH}$ & 0.30 & 6.10 & 0.26 & 5.72 \\
\hline
\end{tabular}

Table 3-6 Average total sodium ion molarities for different solution matricies.

\begin{tabular}{|c|c|c|c|c|}
\hline \multirow[b]{2}{*}{ Component } & \multirow[b]{2}{*}{ Temperature, ${ }^{\circ} \mathrm{C}$} & \multicolumn{3}{|c|}{ Solution Matrix } \\
\hline & & $\begin{array}{l}\text { Unsaturated } \\
\text { with } \mathrm{NaNO}_{3}\end{array}$ & $\begin{array}{c}\text { Saturated with } \\
\mathrm{NaNO}_{3} \\
\end{array}$ & $\begin{array}{c}\text { Saturated with } \mathrm{NaNO}_{3}+ \\
\text { Other Salts }\end{array}$ \\
\hline \multirow[t]{2}{*}{$\mathrm{Na}_{4} \mathrm{EDTA}$} & 40 & 9.6 & 10.2 & - \\
\hline & 50 & 10.1 & 10.5 & - \\
\hline \multirow[t]{2}{*}{$\mathrm{Na}_{3}$ Citrate } & 40 & 8.0 & 9.7 & - \\
\hline & 50 & 7.5 & 10.0 & - \\
\hline \multirow[t]{2}{*}{ NaGlycolate } & 40 & 9.5 & 10.0 & - \\
\hline & 50 & 9.2 & 10.1 & - \\
\hline \multirow[t]{2}{*}{$\mathrm{Na}_{3} \mathrm{NTA}$} & 40 & 9.4 & 10.0 & - \\
\hline & 50 & 9.2 & 10.0 & - \\
\hline \multirow[t]{2}{*}{ Complex Mixture } & 40 & - & - & 14.5 \\
\hline & 50 & - & - & 13.5 \\
\hline
\end{tabular}




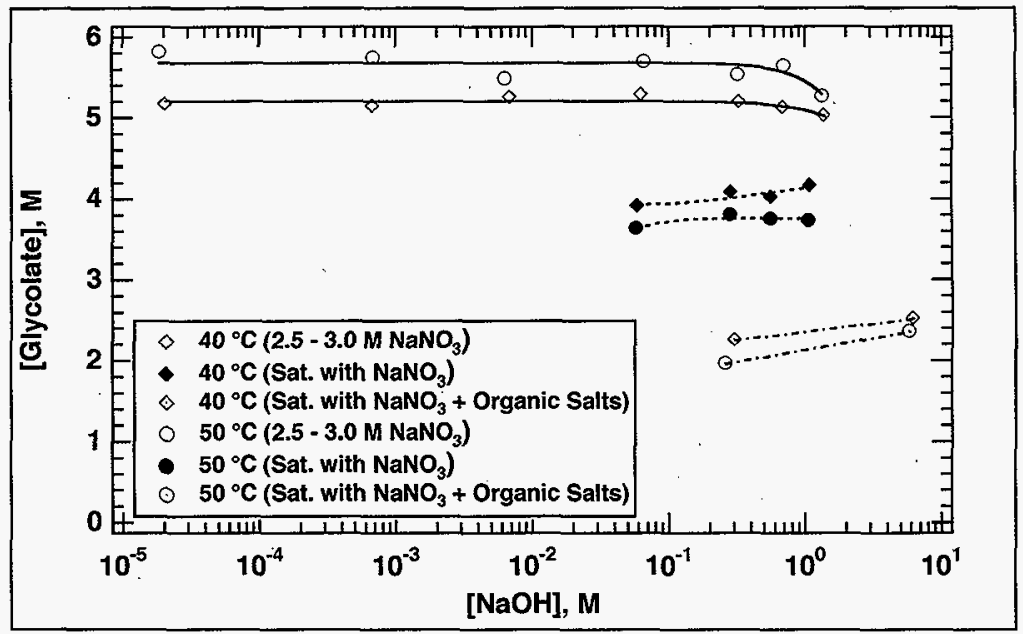

Figure 3-12. Solubility of sodium glycolate in different waste simulant solution matrices at $40^{\circ} \mathrm{C}$ and $50^{\circ} \mathrm{C}$ over a range of sodium hydroxide concentrations.

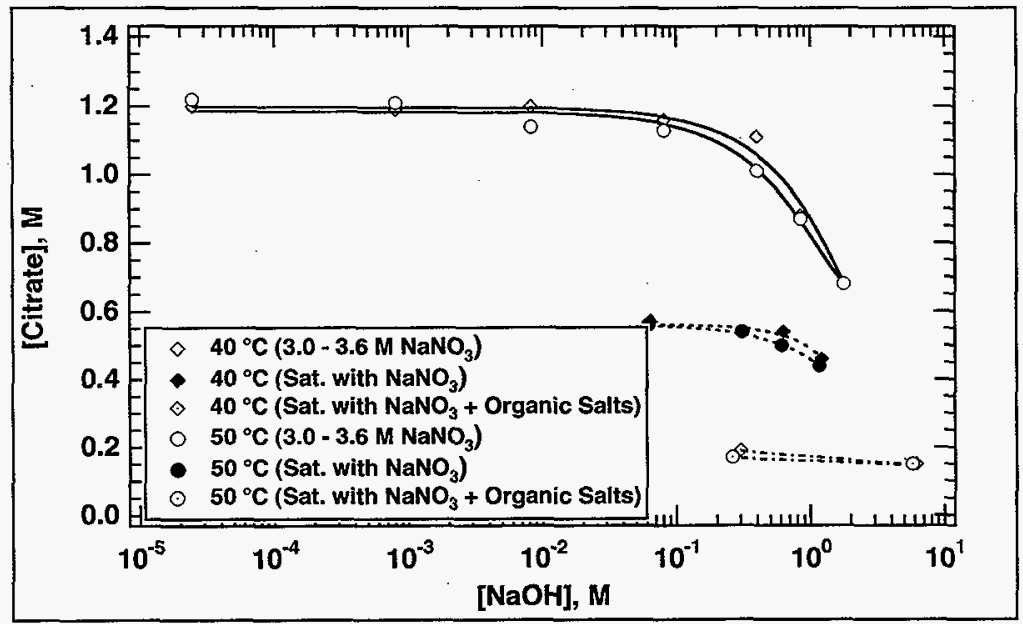

Figure 3-13. Solubility of sodium citrate in different waste simulant solution matrices at $40^{\circ} \mathrm{C}$ and $50^{\circ} \mathrm{C}$ over a range of sodium hydroxide concentrations. 


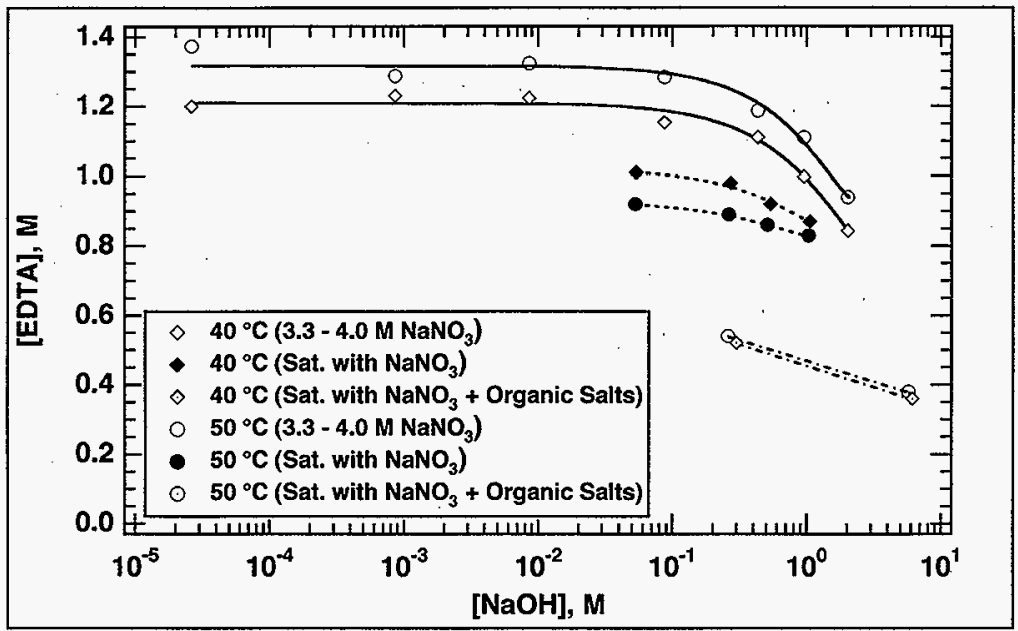

Figure 3-14. Solubility of sodium EDTA in different waste simulant solution matrices at $40^{\circ} \mathrm{C}$ and $50^{\circ} \mathrm{C}$ over a range of sodium hydroxide concentrations.

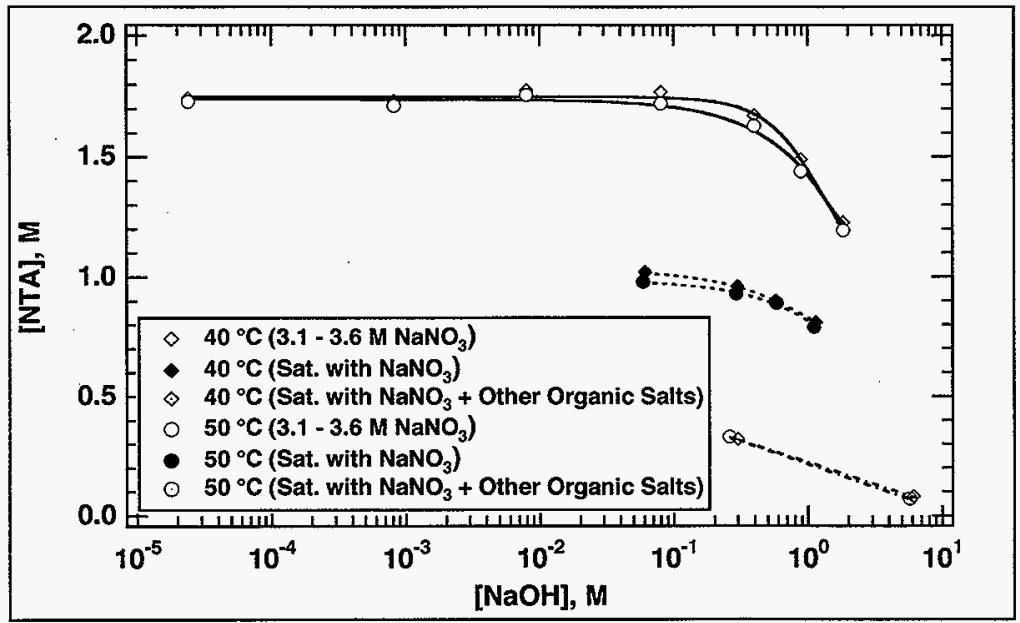

Figure 3-15. Solubility of sodium NTA in different waste simulant solution matrices at $40^{\circ} \mathrm{C}$ and $50^{\circ} \mathrm{C}$ over a range of sodium hydroxide concentrations. 


\subsection{HLW Tank Total Organic Carbon Values}

The solubility data presented above can be used to determine if solid sodium salts of organic compounds can exist in the HLW tanks at the Hanford Site. If concentrations of these salts as measured in the supernate solutions are near the solubility limits measured in this study, then solid organic salts can be presumed to be present in the waste (assuming, of course, that the supernate is in equilibrium with the salts). Ideally, concentrations of the individual salts in actual supernate solutions should be obtained. Unfortunately, only TOC concentrations have been measured in supernate solutions for most of the waste tanks. The TOC values in grams of organic carbon per liter of solution have been collected for supernate solutions in $61 \mathrm{HLW}$ tanks at the Hanford Site. These include values from single-shell tanks (Van Vleet 1993a) and doubleshell tanks (Van Vleet 1993b). The frequency distribution for these 61 values is shown in Figure 3-16. The bulk of the TOC values are less than $14 \mathrm{~g} / \mathrm{L}$ of organic carbon. For single-shell tanks, Toth et al. (1995) have calculated a mean value of $5.2 \pm 1.1 \mathrm{~g} / \mathrm{L}$ organic carbon (at the $95 \%$ confidence level) for the tank supernate solutions. This mean was calculated from analyses of 143 samples from 78 different single-shell tanks.

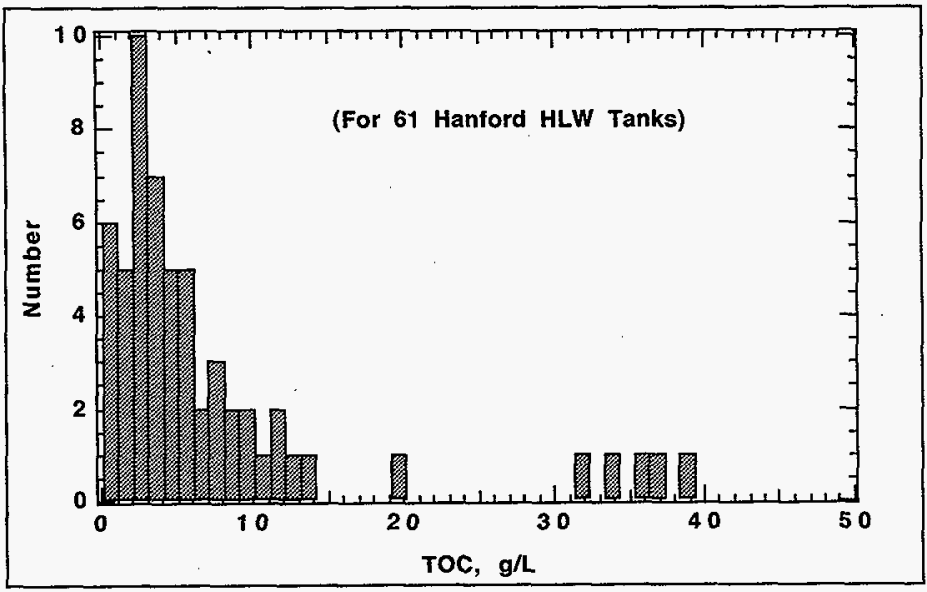

Figure 3-16. Frequency distribution of total organic carbon (TOC) concentrations measured in supernate solutions in 61 different Hanford Site HLW tanks.

If the tank TOC values are compared with solubilities for the nine organic salts studied, only oxalate has a low enough solubility to be present as a solid in the tanks. This can be seen by comparing the TOC values in Table 3-7, which gives the ranges of measured solubilities of the individual organic salts in terms of TOC, with the tank values. Even if all the dissolved organic carbon in the tank supernates is pure acetate, butyrate, glycolate, succinate, caproate, dibutyl phosphate, citrate, formate, EDTA, HEDTA, or NTA, there is not enough in solution to reach saturation and precipitate these organics. 
Table 3-7. Comparison of measured organic sodium salt solubility ranges in units of molarity and total organic carbon concentrations (TOC).

\begin{tabular}{lcccc}
\hline & \multicolumn{2}{c}{ Solutions not saturated with $\mathrm{NaNO}_{3}$} & \multicolumn{2}{c}{ Solutions saturated with $\mathrm{NaNO}_{3}$} \\
\hline Organic salt & Solubility Range*, & TOC Range, $\mathrm{gC} / \mathrm{L}$ & Solubility Range*, & TOC Range, $\mathrm{gC} / \mathrm{L}$ \\
\hline Acetate & $4.0-8.0$ & $96-192$ & $3.8-5.4$ & $91-130$ \\
Glycolate & $4.4-5.8$ & $106-140$ & $3.6-4.2$ & $86-101$ \\
Succinate & $0.9-2.3$ & $43-110$ & $\mathrm{ND}$ & $\mathrm{ND}$ \\
Caproate & $0.2-1.7$ & $14-122$ & $\mathrm{ND}$ & $\mathrm{ND}$ \\
Dibutyphosphate & $>0.9$ & $>86$ & $\mathrm{ND}$ & $\mathrm{ND}$ \\
Oxalate & $0.004-.015$ & $0.1-0.36$ & $0.0012-0.0039$ & $0.029-0.094$ \\
Citrate & $0.6-1.2$ & $43-86$ & $0.35-0.63$ & $25-45$ \\
Formate & $6.8-9.8$ & $82-118$ & $6.6-8.5$ & $79-102$ \\
EDTA & $0.7-1.4$ & $84-168$ & $0.83-1.0$ & $100-120$ \\
NTA & $1.3-1.7$ & $94-122$ & $0.81-1.2$ & $58-86$ \\
Butyrate & $2.6-4.0$ & $125-192$ & $2.2-3.5$ & $106-168$ \\
HEDTA & $1.5-1.8$ & $180-216$ & $1.09-1.19$ & $131-143$ \\
\hline
\end{tabular}

* Over all sodium hydroxide concentrations and temperatures.

$* * \mathrm{ND}=$ not determined.

\subsection{CONCLUSIONS}

The solubilities of sodium acetate in HLW tank supernate solutions measured in the present work are high over the temperature and sodium hydroxide concentration ranges expected in the tanks. Sodium acetate solubilities are similar (in terms of TOC) to sodium citrate, formate, EDTA, HEDTA, NTA, glycolate, succinate, butyrate, caproate, and dibutyl phosphate, which were previously reported (Barney 1994, 1995, and 1996). The high solubilities will prevent solid sodium salts of these eleven organic acids from precipitating from tank supernate solutions. The TOC analyses of actual tank supernates are generally much lower than the TOC ranges for the simulated supernate solutions saturated (at the solubility limit) with the organic salts. This is true even if all the dissolved carbon in a given tank supernate is due to only one of the eleven compounds (a very unlikely situation). Sodium caproate solubility at low temperatures and high hydroxide concentrations is below the TOC for several tanks, but is not expected to be present in high concentrations since it is only one of many possible degradation products of the normal paraffin hydrocarbon (NPH) solvent used in the PUREX process at Hanford (Babad et al. 1993). This compound has not yet been identified in actual waste. The sodium citrate and sodium NTA TOC values are below some tank TOC values when measured in a complex waste mixture, but this simulated mixture had higher total sodium and hydroxide concentrations than expected in actual wastes. Because these eleven organic compounds are not likely to exist as solids in the saltcake or sludge layers of the tanks, but only as aqueous solutions, self-propagating reactions with nitrates or nitrites are unlikely.

The low solubility of sodium oxalate (far below most measured tank supernate TOC values) will allow it to precipitate in some tanks with nitrate and nitrite salts. The energy content of oxalate is quite low and mixtures with sodium nitrate/nitrite will not propagate (Webb et al. 1994). 
No evidence was found that organic complexants can form insoluble precipitates with waste heavy metal ions (such as found in sludge). A small amount of complexant (EDTA) was adsorbed on the surface of iron, nickel, and chromium hydrous oxides at low hydroxide concentrations, but this amount will be insignificant for most wastes. EDTA complexes of nickel and calcium are stable and soluble even at $1.0 \mathrm{M} \mathrm{NaOH}$ in solution. It is likely that most of the complexants in the wastes exist as metal complexes in the aqueous phase of the wastes.

\subsection{FUTURE WORK}

Solubilities of additional organic compounds known to exist in the HLW tanks will be measured. These include compounds that have been found in actual tank waste recently by Campbell et al., 1994, 1995, and 1996. They are sodium iminodiacetate, $\mathrm{NH}\left(\mathrm{CH}_{2} \mathrm{COONa}\right)_{2}$ and sodium bis(2-ethylhexyl) phosphate, $\mathrm{NaC}_{16} \mathrm{H}_{34} \mathrm{O}_{4} \mathrm{P}$. Experimental work has been completed for these compounds and for mixtures of organic salts and the solubility measurements only require analyses of solution samples. Analysis is also required for measuring adsorption/precipitation on other metal hydrous oxides $\left(\mathrm{Al}^{3+}, \mathrm{Bi}^{3+}, \mathrm{Ca}^{2+}\right.$, and $\left.\mathrm{ZrO}^{2+}\right)$.

\subsection{REFERENCES}

Ashby, E. C., A. Annis, E. K. Barefield, D. Boatright, F. Doctorovich, C. L. Liotta, H. M. Neumann, A. Konda, C.-F. Yao, K. Zang, and N. G. Duffie, 1994, "Synthetic Waste Mechanism Studies," WHC-EP-0823, Westinghouse Hanford Company, Richland, Washington.

Babad, H., D. M. Camaioni, M. A. Lilga, and D. M. Strachan, 1993, "Tank Waste Chemistry - A New Understanding of Waste Aging," WHC-SA-I694-FP, Westinghouse Hanford Company, Richland, Washington.

Barney, G. S., 1994, "The Solubilities of Significant Organic Compounds in HLW Tank Supernate Solutions," WHC-SA-2565-FP, Westinghouse Hanford Company, Richland, Washington.

Barney, G. S., 1995, "The Solubilities of Significant Organic Compounds in HLW Tank Supernate Solutions -FY1995 Progress Report", WHC-EP-0899, Westinghouse Hanford Company, Richland, Washington.

Barney, G. S., 1996, "Solubilities of Significant Organic Compounds in HLW Tank Supernate Solutions - FY 1996 Progress Report,".WHC-EP-0899-1, Westinghouse Hanford Company, Richland, Washington.

Blesa, M. A., E. B. Borghi, J. G. Maroto, and A. E. Regazzoni, 1984, "Adsorption of EDTA and Iron-EDTA Complexes on Magnetite and the Mechanism of Dissolution of Magnetite by EDTA," J. Coll. and Interface Sci., 98, 295-305.

Bowers, A. R. and C. P. Huang, 1987, "Role of Fe(III) in Metal Complex Adsorption by Hydrous Solids," Wat. Res., 21, 757-764.

Camaioni, D. M., W. D. Samuals, B. D. Lenihan, S. A. Clauss, K.L. Wahl, J. A. Campbell, and W. J. Shaw, 1995, "Organic Tanks Safety Program FY95 Waste Aging Studies", PNL-10161, Pacific Northwest National Laboratory, Richland, Washington.

Camaioni, D. M., W. D. Samuals, B. D. Lenihan, S. A. Clauss, A. K. Sharma, K.L. Wahl, and J. A. Campbell, 1996, "Organic Tanks Safety Program FY96 Waste Aging Studies", PNL-11312, Pacific Northwest National Laboratory, Richland, Washington. 


\section{HNF-EP-0899-2}

Campbell, J. A., S. Clauss, K. Grant, V. Hoopes, B. Lerner, R. Lucke, G. Mong, J. Rau, and R. Steele, 1994, "Flammable Gas Safety Program - Analytical Methods Development: FY 1993 Progress Report," PNL9062, Pacific Northwest Laboratory, Richland, Washington.

Campbell, J. A., S. Clauss, K. Grant, V. Hoopes, G. Mong, J. Rau, R. Scheele, K. L. Wahl, 1995, "Organic Analysis and Analytical Development: FY 1995 Progress Report," PNL-10776, Pacific Northwest Laboratory, Richland, Washington.

Campbell, J. A., S. A. Clauss, K. E. Grant, V. Hoopes, G. M. Mong, J. Rau, R. Scheele, K. L. Wahl, 1996, "Flammable Gas Safety Program:Actual Waste Organic Analysis: FY 1996 Progress Report," PNL11307, Pacific Northwest Laboratory, Richland, Washington.

Chang, H-C. and E. Matijevic, 1983, "Interactions of Metal Hydrous Oxides with Chelating Agents. IV. Dissolution of Hematite," J. Coll. and Interface Sci., 92, 479 - 488.

Morgan, R. A. and R. R. Walker, Jr., 1945, Ind. Eng. Chem., 36, 1186-8.

Nowack, B. and L. Sigg, 1996, "Adsorption of EDTA and Metal-EDTA Complexes onto Goethite," J. Coll. and Interface Sci., 177, 106-121.

Nowack, B., J. Lutzenkirchen, P. Behra, and L. Sigg, 1996, "Modeling the Adsorption of Metal-EDTA Complexes onto Oxides, "Environ. Sci. Technol., 30, 2397-2405.

Nowack, B. and L. Sigg, 1997, "Dissolution of Fe(III)(hydr)oxides by Metal-EDTA Complexes," Geochim. et Cosmochim. Acta, 61, 951-963.

Toste, A. P., T. J. Lechner-Fish, D. J. Hendren, R. D. Scheele, and W. G. Richmond, 1988, "Analysis of Organics in Highly Radioactive Wastes", J. Radioanal. and Nucl. Chem., Art., 123:149-166.

Toth, J. J., J. G. Hill, P. G. Heasler, P. D. Whitney, and M. E. Lerchen, 1995, "Analysis of Organic Carbon and Moisture in Hanford Single-Shell Tank Waste", PNL-10360, Pacific Northwest Laboratory, Richland, Washington.

Van Vleet, R. J., 1993a, "Radionuclide and Chemical Inventories for the Single Shell Tanks," WHC-SD-WM-TI565, Westinghouse Hanford Company, Richland, Washington.

Van Vleet, R. J., 1993b, "Radionuclide and Chemical Inventories for the Double Shell Tanks," WHC-SD-WM-TI543, Westinghouse Hanford Company, Richland, Washington.

Webb, A. L., J. L. Stewart, M. G. Plys, B. Malinovuic, J. M. Grigsby, D. M. Camaioni, P. Heasler, and J. J. Toth, 1995, "Preliminary Safety Criteria for Organic Watchlist Tanks at the Hanford Site", WHC-SD. SARR-033 Rev. 0, Westinghouse Hanford Company, Richland, Washington. 
HNF-EP-0899-2

\section{APPENDIX}

SOLUBILITIES OF ORGANIC SALTS AND SOLUTION COMPOSITIONS 
HNF-EP-0899-2

Acetate Solubilities

(Molar Concentrations)

\begin{tabular}{|c|c|c|c|c|}
\hline \multirow{2}{*}{$\begin{array}{l}\text { Initial } \\
\text { [NaOH] }\end{array}$} & \multicolumn{4}{|c|}{ EQUILIBRIUM SOLUBILITIES } \\
\hline & [Acetate],50 ${ }^{\circ} \mathrm{C}$ & {$\left[\right.$ Acetate], $40^{\circ} \mathrm{C}$} & [Acetate], $30^{\circ} \mathrm{C}$ & [Acetate], $25^{\circ} \mathrm{C}$ \\
\hline 0.00003 & 7.97 & 6.48 & 5.76 & 5.26 \\
\hline 0.001 & 7.94 & 6.19 & 5.26 & 4.99 \\
\hline 0.01 & 8.01 & 6.28 & 5.31 & 5.62 \\
\hline $0.1^{-}$ & 7.91 & 6.29 & 5.47 & 5.05 \\
\hline 0.5 & 7.46 & 6.20 & 5.42 & 4.67 \\
\hline 1 & 7.28 & 6.30 & 5.48 & 5.01 \\
\hline \multirow[t]{2}{*}{2} & 7.06 & 5.94 & 4.56 & 4.02 \\
\hline & {$\left[\mathrm{NaNO}_{3}\right], 50^{\circ} \mathrm{C}$} & {$\left[\mathrm{NaNO}_{3}\right], 40^{\circ} \mathrm{C}$} & {$\left[\mathrm{NaNO}_{3}\right], 30^{\circ} \mathrm{C}$} & {$\left[\mathrm{NaNO}_{3}\right], 25^{\circ} \mathrm{C}$} \\
\hline 0.00003 & 0.533 & 0.628 & 0.644 & 0.660 \\
\hline 0.001 & 0.965 & 1.180 & 0.997 & 0.803 \\
\hline 0.01 & 0.397 & 0.393 & 0.383 & 0.392 \\
\hline 0.1 & 0.955 & 1.102 & 1.170 & 1.287 \\
\hline 0.5 & 0.907 & 1.290 & 1.138 & 1.760 \\
\hline 1 & 0.556 & 0.741 & 0.746 & 0.907 \\
\hline \multirow[t]{2}{*}{2} & 1.120 & 1.603 & 2.040 & 2.487 \\
\hline & {$\left[\mathrm{NaNO}_{2}\right], 50^{\circ} \mathrm{C}$} & {$\left[\mathrm{NaNO}_{2}\right], 40^{\circ} \mathrm{C}$} & {$\left[\mathrm{NaNO}_{2}\right], 30^{\circ} \mathrm{C}$} & {$\left[\mathrm{NaNO} \mathrm{O}_{2}\right], 25^{\circ} \mathrm{C}$} \\
\hline 0.00003 & 0.141 & 0.158 & 0.165 & 0.171 \\
\hline 0.001 & 0.255 & 0.302 & 0.256 & 0.208 \\
\hline 0.01 & 0.100 & 0.098 & 0.094 & 0.099 \\
\hline 0.1 & 0.242 & 0.296 & 0.307 & 0.337 \\
\hline 0.5 & 0.227 & 0.340 & 0.299 & 0.445 \\
\hline 1 & 0.138 & 0.187 & 0.195 & 0.228 \\
\hline \multirow[t]{2}{*}{2} & 0.269 & 0.414 & 0.513 & 0.623 \\
\hline & {$[\mathrm{NaOH}], 50^{\circ} \mathrm{C}$} & {$[\mathrm{NaOH}], 40^{\circ} \mathrm{C}$} & {$[\mathrm{NaOH}], 30^{\circ} \mathrm{C}$} & {$[\mathrm{NaOH}], 25^{\circ} \mathrm{C}$} \\
\hline 0.00003 & $4.23 \mathrm{E}-06$ & $4.75 \mathrm{E}-06$ & $4.95 \mathrm{E}-06$ & $5.12 \mathrm{E}-06$ \\
\hline 0.001 & 2.55E-04 & $3.02 \mathrm{E}-04$ & $2.56 \mathrm{E}-04$ & $2.08 \mathrm{E}-04$ \\
\hline 0.01 & $9.98 \mathrm{E}-04$ & $9.76 \mathrm{E}-04$ & $9.43 \mathrm{E}-04$ & $9.85 \mathrm{E}-04$ \\
\hline 0.1 & $2.42 \mathrm{E}-02$ & $2.96 \mathrm{E}-02$ & $3.07 \mathrm{E}-02$ & $3.37 \mathrm{E}-02$ \\
\hline 0.5 & $1.14 \mathrm{E}-01$ & $1.70 \mathrm{E}-01$ & $1.50 \mathrm{E}-01$ & $2.23 \mathrm{E}-01$ \\
\hline 1 & $1.38 \mathrm{E}-01$ & $1.87 \mathrm{E}-01$ & $1.95 \mathrm{E}-01$ & $2.28 \mathrm{E}-01$ \\
\hline 2 & $5.37 \mathrm{E}-01$ & $8.28 \mathrm{E}-01$ & $1.03 E+00$ & $1.25 \mathrm{E}+00$ \\
\hline
\end{tabular}


HNF-EP-0899-2

Acetate Solubilities In Saturated $\mathrm{NaNO}_{3}$ Solution (Molar Concentrations)

\begin{tabular}{|c|c|c|c|c|}
\hline \multirow{2}{*}{$\begin{array}{l}\text { Initial } \\
\text { [NaOH] }\end{array}$} & \multicolumn{4}{|c|}{ EQUILIBRIUM SOLUBILITIES } \\
\hline & [Acetate], $50^{\circ} \mathrm{C}$ & [Acetate], $40^{\circ} \mathrm{C}$ & [Acetate], $30^{\circ} \mathrm{C}$ & [Acetate], $25^{\circ} \mathrm{C}$ \\
\hline 0.1 & 5.03 & 5.44 & 4.96 & 4.16 \\
\hline 0.5 & 5.20 & 5.35 & 4.66 & 4.13 \\
\hline 1 & 4.81 & 5.18 & 4.45 & 4.07 \\
\hline \multirow[t]{2}{*}{2} & 5.10 & 5.31 & 4.17 & 3.79 \\
\hline & {$\left[\mathrm{NaNO}_{3}\right], 50^{\circ} \mathrm{C}$} & {$\left[\mathrm{NaNO}_{3}\right], 40^{\circ} \mathrm{C}$} & {$\left[\mathrm{NaNO}_{3}\right], 30^{\circ} \mathrm{C}$} & {$\left[\mathrm{NaNO}_{3}\right], 25^{\circ} \mathrm{C}$} \\
\hline 0.1 & 4.50 & 4.01 & 3.58 & 3.65 \\
\hline 0.5 & 4.64 & 3.95 & 3.65 & 3.65 \\
\hline 1 & 4.62 & 3.94 & 3.61 & 3.66 \\
\hline \multirow[t]{2}{*}{2} & 4.38 & 3.67 & 3.43 & 3.48 \\
\hline & {$\left[\mathrm{NaNO}_{2}\right], 50^{\circ} \mathrm{C}$} & {$\left[\mathrm{NaNO}_{2}, 40^{\circ} \mathrm{C}\right.$} & {$\left[\mathrm{NaNO}_{2}\right], 30^{\circ} \mathrm{C}$} & {$\left[\mathrm{NaNO}_{2}\right], 25^{\circ} \mathrm{C}$} \\
\hline 0.1 & 0.91 & 0.97 & 1.07 & 1.20 \\
\hline 0.5 & 0.93 & 0.95 & 1.09 & 1.20 \\
\hline 1 & 0.87 & 0.91 & 1.03 & 1.15 \\
\hline \multirow[t]{2}{*}{2} & 0.86 & 0.88 & 1.07 & 1.20 \\
\hline & {$[\mathrm{NaOH}], 50^{\circ} \mathrm{C}$} & {$[\mathrm{NaOH}], 40^{\circ} \mathrm{C}$} & {$[\mathrm{NaOH}], 30^{\circ} \mathrm{C}$} & {$[\mathrm{NaOH}], 25^{\circ} \mathrm{C}$} \\
\hline 0.1 & 0.05 & 0.05 & 0.05 & 0.06 \\
\hline 0.5 & 0.23 & 0.24 & 0.27 & 0.30 \\
\hline 1 & 0.43 & 0.45 & 0.52 & 0.58 \\
\hline 2 & 0.86 & 0.88 & 1.07 & 1.20 \\
\hline
\end{tabular}


Glycolate Solubilities In Saturated $\mathrm{NaNO}_{3}$ Solutions (Molar Concentrations)

\begin{tabular}{|c|c|c|c|c|}
\hline \multirow{2}{*}{$\begin{array}{l}\text { Initial } \\
{[\mathrm{NaOH}]}\end{array}$} & \multicolumn{4}{|c|}{ EQUILIBRIUM SOLUBILITIES } \\
\hline & {$[G L Y], 50^{\circ} \mathrm{C}$} & {$[G L Y], 40^{\circ} \mathrm{C}$} & {$[G L Y], 30^{\circ} \mathrm{C}$} & {$[G L Y], 25^{\circ} \mathrm{C}$} \\
\hline 0.1 & 3.64 & 3.92 & 4.12 & 4.11 \\
\hline 0.5 & 3.81 & 4.09 & 4.17 & 4.13 \\
\hline 1 & 3.76 & 4.03 & 4.13 & 4.16 \\
\hline \multirow[t]{2}{*}{2} & 3.74 & 4.17 & 4.18 & 4.10 \\
\hline & {$\left[\mathrm{NaNO}_{3}\right], 50^{\circ} \mathrm{C}$} & {$\left[\mathrm{NaNO} \mathrm{O}_{3}\right], 40^{\circ} \mathrm{C}$} & {$\left[\mathrm{NaNO}_{3}\right], 30^{\circ} \mathrm{C}$} & $\mathrm{INaNO} \mathrm{O}_{3} l, 25^{\circ} \mathrm{C}$ \\
\hline 0.1 & 5.69 & 5.16 & 4.65 & 4.31 \\
\hline 0.5 & 5.26 & 4.98 & 4.46 & 4.28 \\
\hline 1 & 5.33 & 4.96 & 4.37 & 4.15 \\
\hline \multirow[t]{2}{*}{2} & 4.95 & 4.64 & 4.02 & 3.66 \\
\hline & {$\left[\mathrm{NaNO}_{2}\right], 50^{\circ} \mathrm{C}$} & {$\left[\mathrm{NaNO}_{2}\right], 40^{\circ} \mathrm{C}$} & {$\left[\mathrm{NaNO} \mathrm{O}_{2}\right], 30^{\circ} \mathrm{C}$} & {$\left[\mathrm{NaNO}_{2}\right], 25^{\circ} \mathrm{C}$} \\
\hline 0.1 & 1.17 & 1.17 & 1.21 & 1.20 \\
\hline 0.5 & 1.13 & 1.14 & 1.17 & 1.20 \\
\hline 1 & 1.12 & 1.13 & 1.15 & 1.17 \\
\hline \multirow[t]{2}{*}{2} & 1.06 & 1.09 & 1.08 & 1.07 \\
\hline & {$[\mathrm{NaOH}], 50^{\circ} \mathrm{C}$} & {$[\mathrm{NaOH}], 40^{\circ} \mathrm{C}$} & {$[\mathrm{NaOH}], 30^{\circ} \mathrm{C}$} & {$[\mathrm{NaOH}], 25^{\circ} \mathrm{C}$} \\
\hline 0.1 & 0.058 & 0.059 & 0.060 & 0.060 \\
\hline 0.5 & 0.283 & 0.286 & 0.292 & 0.299 \\
\hline 1 & 0.562 & 0.565 & 0.573 & 0.585 \\
\hline 2 & 1.063 & 1.087 & 1.080 & 1.067 \\
\hline
\end{tabular}


HNF-EP-0899-2

Citrate Solubilities In Saturated $\mathrm{NaNO}_{3}$ Solutions (Molar Concentrations)

\begin{tabular}{|c|c|c|c|c|}
\hline \multirow{2}{*}{$\begin{array}{l}\text { Initial } \\
{[\mathrm{NaOH}]}\end{array}$} & \multicolumn{4}{|c|}{ EQUILIBRIUM SOLUBILITIES } \\
\hline & {$[\mathrm{CIT}], 50^{\circ} \mathrm{C}$} & {$[C I T], 40^{\circ} \mathrm{C}$} & {$[C I T], 30^{\circ} \mathrm{C}$} & {$[C I T], 25^{\circ} \mathrm{C}$} \\
\hline 0.1 & 0.56 & 0.57 & 0.52 & 0.63 \\
\hline 0.5 & 0.54 & 0.54 & 0.48 & 0.35 \\
\hline 1 & 0.50 & 0.54 & 0.51 & 0.54 \\
\hline \multirow[t]{2}{*}{2} & 0.44 & 0.46 & 0.42 & 0.42 \\
\hline & {$\left[\mathrm{NaNO} \mathrm{O}_{3} l, 50^{\circ} \mathrm{C}\right.$} & {$\left[\mathrm{NaNO}_{3} /, 40^{\circ} \mathrm{C}\right.$} & {$\left[\mathrm{NaNO}_{3}\right], 30^{\circ} \mathrm{C}$} & {$\left[\mathrm{NaNO} \mathrm{O}_{3}\right], 25^{\circ} \mathrm{C}$} \\
\hline 0.1 & 6.78 & 6.33 & 5.80 & 5.46 \\
\hline 0.5 & 6.61 & 6.20 & 5.78 & 5.64 \\
\hline 1 & 6.37 & 6.03 & 5.45 & 5.16 \\
\hline \multirow[t]{2}{*}{2} & 6.26 & 5.66 & 5.17 & 4.82 \\
\hline & {$\left[\mathrm{NaNO}_{2}\right], 50^{\circ} \mathrm{C}$} & $\mathrm{NaNO}_{2} \mathrm{l}, 40^{\circ} \mathrm{C}$ & $\left.\mathrm{NaNO}_{2}\right], 30^{\circ} \mathrm{C}$ & {$\left[\mathrm{NaNO}_{2} \mathrm{l}, 25^{\circ} \mathrm{C}\right.$} \\
\hline 0.1 & 1.24 & 1.28 & 1.31 & 1.33 \\
\hline 0.5 & 1.24 & 1.26 & 1.29 & 1.30 \\
\hline 1 & 1.22 & 1.26 & 1.29 & 1.30 \\
\hline \multirow[t]{2}{*}{2} & 1.16 & 1.21 & 1.26 & 1.24 \\
\hline & {$[\mathrm{NaOH}], 50^{\circ} \mathrm{C}$} & {$[\mathrm{NaOH}], 40^{\circ} \mathrm{C}$} & {$[\mathrm{NaOH}], 30^{\circ} \mathrm{C}$} & {$[\mathrm{NaOH}], 25^{\circ} \mathrm{C}$} \\
\hline $0: 1$ & 0.06 & 0.06 & 0.07 & 0.07 \\
\hline 0.5 & 0.31 & 0.31 & 0.32 & 0.33 \\
\hline 1 & 0.61 & 0.63 & 0.65 & 0.65 \\
\hline 2 & 1.16 & 1.21 & 1.26 & 1.24 \\
\hline
\end{tabular}


Formate Solubilities In Saturated $\mathrm{NaNO}_{3}$ Solutions (Molar Concentrations)

\begin{tabular}{|c|c|c|c|c|}
\hline \multirow{2}{*}{$\begin{array}{l}\text { Initial } \\
{[\mathrm{NaOH}]}\end{array}$} & \multicolumn{4}{|c|}{ EQUILIBRIUM SOLUBILITIES } \\
\hline & {$[F O R], 50{ }^{\circ} \mathrm{C}$} & {$[F O R], 40^{\circ} \mathrm{C}$} & {$[F O R], 30^{\circ} \mathrm{C}$} & {$[F O R], 25^{\circ} \mathrm{C}$} \\
\hline 0.1 & 7.96 & 8.31 & 8.34 & 8.52 \\
\hline 0.5 & 6.91 & 7.41 & 7.70 & 7.78 \\
\hline 1 & 7.17 & 7.53 & 7.53 & 7.43 \\
\hline \multirow[t]{2}{*}{2} & 6.64 & 6.97 & 7.13 & 7.25 \\
\hline & {$\left[\mathrm{NaNO}_{3}\right], 50^{\circ} \mathrm{C}$} & {$\left[\mathrm{NaNO}_{3}\right], 40^{\circ} \mathrm{C}$} & {$\left[\mathrm{NaNO}_{3}\right], 30^{\circ} \mathrm{C}$} & {$\left[\mathrm{NaNO} \mathrm{O}_{3}, 25^{\circ} \mathrm{C}\right.$} \\
\hline 0.1 & 3.72 & 4.14 & 4.08 & 3.79 \\
\hline 0.5 & 5.18 & 4.64 & 4.07 & 3.98 \\
\hline 1 & 4.71 & 4.49 & 3.85 & 3.70 \\
\hline \multirow[t]{2}{*}{2} & 3.89 & 4.26 & 3.78 & 3.56 \\
\hline & {$\left[\mathrm{NaNO} \mathrm{O}_{2}\right], 50^{\circ} \mathrm{C}$} & {$\left[\mathrm{NaNO}_{2}\right], 40^{\circ} \mathrm{C}$} & {$\left[\mathrm{NaNO} \mathrm{N}_{2}\right], 30^{\circ} \mathrm{C}$} & {$\left[\mathrm{NaNO}_{2}\right], 25^{\circ} \mathrm{C}$} \\
\hline 0.1 & 1.19 & 1.19 & 1.16 & 1.16 \\
\hline 0.5 & 1.21 & 1.17 & 1.17 & 1.18 \\
\hline 1 & 1.14 & 1.11 & 1.10 & 1.10 \\
\hline \multirow[t]{2}{*}{2} & 1.11 & 1.11 & 1.10 & 1.09 \\
\hline & {$[\mathrm{NaOH}], 50^{\circ} \mathrm{C}$} & {$[\mathrm{NaOH}], 40^{\circ} \mathrm{C}$} & {$[\mathrm{NaOH}], 30^{\circ} \mathrm{C}$} & {$[\mathrm{NaOH}], 25^{\circ} \mathrm{C}$} \\
\hline 0.1 & 0.059 & 0.059 & 0.058 & 0.058 \\
\hline 0.5 & 0.302 & 0.292 & 0.293 & 0.295 \\
\hline 1 & 0.57 & 0.55 & 0.55 & 0.55 \\
\hline 2 & 1.11 & 1.11 & 1.10 & 1.09 \\
\hline
\end{tabular}


HNF-EP-0899-2

\section{EDTA Solubilities In Saturated $\mathrm{NaNO}_{3}$ Solutions}

(Molar Concentrations)

\begin{tabular}{|c|c|c|c|c|}
\hline \multirow{2}{*}{$\begin{array}{l}\text { Initial } \\
{[\mathrm{NaOH}]}\end{array}$} & \multicolumn{4}{|c|}{ EQUILIBRIUM SOLUBILITIES } \\
\hline & $\lfloor E D T A\rceil, 50^{\circ} \mathrm{C}$ & {$[E D T A], 40^{\circ} \mathrm{C}$} & {$[E D T A], 30^{\circ} \mathrm{C}$} & {$[E D T A], 25^{\circ} \mathrm{C}$} \\
\hline 0.1 & 0.92 & 1.01 & 0.99 & 0.95 \\
\hline 0.5 & 0.89 & 0.98 & 0.96 & 0.91 \\
\hline 1 & 0.86 & 0.92 & 0.92 & 0.89 \\
\hline \multirow[t]{2}{*}{2} & 0.83 & 0.87 & 0.87 & 0.85 \\
\hline & {$\left[\mathrm{NaNO}_{3}\right], 50^{\circ} \mathrm{C}$} & {$\left[\mathrm{NaNO}_{3}\right], 40^{\circ} \mathrm{C}$} & {$\left[\mathrm{NaNO}_{3}\right], 30^{\circ} \mathrm{C}$} & {$\left[\mathrm{NaNO}_{3}\right], 25^{\circ} \mathrm{C}$} \\
\hline 0.1 & 5.09 & 4.65 & 4.31 & 3.93 \\
\hline 0.5 & 5.23 & 4.72 & 4.23 & 3.87 \\
\hline 1 & 5.01 & 4.69 & 4.17 & 3.74 \\
\hline \multirow[t]{2}{*}{2} & 5.10 & 4.47 & 3.89 & 3.70 \\
\hline & {$\left[\mathrm{NaNO} \mathrm{O}_{2}\right], 50^{\circ} \mathrm{C}$} & {$\left[\mathrm{NaNO}_{2}\right], 40^{\circ} \mathrm{C}$} & {$\left[\mathrm{NaNO}_{2}\right], 30^{\circ} \mathrm{C}$} & {$\left[\mathrm{NaNO}_{2} /, 25^{\circ} \mathrm{C}\right.$} \\
\hline 0.1 & 1.05 & 1.07 & 1.15 & 1.14 \\
\hline 0.5 & 1.05 & 1.09 & 1.13 & 1.11 \\
\hline 1 & 1.02 & 1.08 & 1.12 & 1.09 \\
\hline \multirow[t]{2}{*}{2} & 1.03 & 1.05 & 1.07 & 1.09 \\
\hline & {$[\mathrm{NaOH}], 50^{\circ} \mathrm{C}$} & {$[\mathrm{NaOH}], 40^{\circ} \mathrm{C}$} & {$[\mathrm{NaOH}], 30^{\circ} \mathrm{C}$} & {$[\mathrm{NaOH}], 25^{\circ} \mathrm{C}$} \\
\hline 0.1 & 0.053 & 0.054 & 0.058 & 0.057 \\
\hline 0.5 & 0.263 & 0.273 & 0.283 & 0.278 \\
\hline 1 & 0.51 & 0.54 & 0.56 & 0.54 \\
\hline 2 & 1.03 & 1.05 & 1.07 & 1.09 \\
\hline
\end{tabular}




\begin{tabular}{|c|c|c|c|c|}
\hline \multirow{2}{*}{$\begin{array}{l}\text { Initial } \\
{[\mathrm{NaOH}]}\end{array}$} & \multicolumn{4}{|c|}{ EQUILIIBRIUM SOLUBILITIES } \\
\hline & {$[N T A], 50^{\circ} \mathrm{C}$} & {$[N T A], 40^{\circ} \mathrm{C}$} & {$[N T A], 30^{\circ} \mathrm{C}$} & {$[N T A], 25^{\circ} \mathrm{C}$} \\
\hline 0.1 & 0.98 & 1.02 & 1.09 & 1.15 \\
\hline 0.5 & 0.93 & 0.96 & 1.04 & 1.10 \\
\hline 1 & 0.89 & 0.90 & 0.96 & 1.05 \\
\hline \multirow[t]{2}{*}{2} & 0.82 & 0.81 & 0.84 & 0.91 \\
\hline & {$\left[\mathrm{NaNO}_{3}\right], 50^{\circ} \mathrm{C}$} & {$\left[\mathrm{NaNO}_{3}\right], 40^{\circ} \mathrm{C}$} & {$\left[\mathrm{NaNO}_{3}\right], 30^{\circ} \mathrm{C}$} & $\left.\mathrm{INaNO}_{3}\right], 25^{\circ} \mathrm{C}$ \\
\hline 0.1 & 5.42 & 5.21 & 4.59 & 4.36 \\
\hline 0.5 & 5.48 & 5.10 & 4.69 & 4.24 \\
\hline 1 & 5.29 & 4.88 & 4.54 & 3.99 \\
\hline \multirow[t]{2}{*}{2} & 5.00 & 4.83 & 4.23 & 4.04 \\
\hline & {$\left[\mathrm{NaNO}_{2}\right], 50^{\circ} \mathrm{C}$} & {$\left[\mathrm{NaNO}_{2}\right], 40^{\circ} \mathrm{C}$} & {$\left[\mathrm{NaNO}_{2}\right], 30^{\circ} \mathrm{C}$} & {$\left[\mathrm{NaNO}_{2}\right], 25^{\circ} \mathrm{C}$} \\
\hline 0.1 & 1.18 & 1.21 & 1.21 & 1.25 \\
\hline 0.5 & 1.17 & 1.19 & 1.26 & 1.23 \\
\hline 1 & 1.17 & 1.15 & 1.24 & 1.17 \\
\hline \multirow[t]{2}{*}{2} & 1.12 & 1.15 & 1.17 & 1.16 \\
\hline & {$[\mathrm{NaOH}], 50^{\circ} \mathrm{C}$} & {$[\mathrm{NaOH}], 40^{\circ} \mathrm{C}$} & {$[\mathrm{NaOH}], 30^{\circ} \mathrm{C}$} & {$[\mathrm{NaOH}], 25^{\circ} \mathrm{C}$} \\
\hline 0.1 & 0.06 & 0.06 & 0.06 & 0.06 \\
\hline 0.5 & 0.29 & 0.30 & 0.32 & 0.31 \\
\hline 1 & 0.58 & 0.58 & 0.62 & 0.59 \\
\hline 2 & 1.12 & 1.15 & 1.17 & 1.16 \\
\hline
\end{tabular}


Oxalate Solubilities In Saturated $\mathrm{NaNO}_{3}$ Solutions (Molar Concentrations)

\begin{tabular}{|c|c|c|c|c|}
\hline \multirow{2}{*}{$\begin{array}{l}\text { Initial } \\
{[\mathrm{NaOH}]}\end{array}$} & \multicolumn{4}{|c|}{ EQUILIBRIUM SOLUBILITIES } \\
\hline & [Oxalate], $50^{\circ} \mathrm{C}$ & IOxalate, $40^{\circ} \mathrm{C}$ & [Oxalate], $30^{\circ} \mathrm{C}$ & [Oxalate], $25^{\circ} \mathrm{C}$ \\
\hline 0.1 & 0.00144 & 0.00131 & 0.00285 & 0.00120 \\
\hline 0.5 & 0.00216 & 0.00183 & 0.00307 & 0.00152 \\
\hline 1 & 0.00311 & 0.00365 & 0.00386 & 0.00236 \\
\hline \multirow[t]{2}{*}{2} & 0.00313 & 0.00318 & 0.00313 & 0.00243 \\
\hline & {$\left[\mathrm{NaNO}_{3}\right], 50^{\circ} \mathrm{C}$} & {$\left[\mathrm{NaNO}_{3}\right], 40^{\circ} \mathrm{C}$} & {$\left[\mathrm{NaNO}_{3}\right], 30^{\circ} \mathrm{C}$} & {$\left[\mathrm{NaNO}_{3}\right], 25^{\circ} \mathrm{C}$} \\
\hline 0.1 & 7.83 & 7.33 & 6.78 & 6.52 \\
\hline 0.5 & 7.18 & 7.04 & 6.47 & 6.22 \\
\hline 1 & 7.30 & 6.72 & 6.22 & 5.89 \\
\hline \multirow[t]{2}{*}{2} & 6.62 & 6.14 & 5.75 & 5.48 \\
\hline & {$\left[\mathrm{NaNO}_{2}\right], 50^{\circ} \mathrm{C}$} & {$\left[\mathrm{NaNO}_{2}\right], 40^{\circ} \mathrm{C}$} & {$\left[\mathrm{NaNO}_{2}\right], 30^{\circ} \mathrm{C}$} & {$\left[\mathrm{NaNO} \mathrm{O}_{2}\right], 25^{\circ} \mathrm{C}$} \\
\hline 0.1 & 1.40 & 1.45 & 1.48 & 1.48 \\
\hline 0.5 & 1.38 & 1.40 & 1.43 & 1.43 \\
\hline 1 & 1.35 & 1.39 & 1.40 & 1.38 \\
\hline \multirow[t]{2}{*}{2} & 1.30 & 1.31 & 1.39 & 1.38 \\
\hline & {$[\mathrm{NaOH}], 50^{\circ} \mathrm{C}$} & {$[\mathrm{NaOH}], 40^{\circ} \mathrm{C}$} & {$[\mathrm{NaOH}], 30^{\circ} \mathrm{C}$} & {$[\mathrm{NaOH}], 25^{\circ} \mathrm{C}$} \\
\hline 0.1 & 0.070 & 0.073 & 0.074 & 0.074 \\
\hline 0.5 & 0.344 & 0.351 & 0.358 & 0.358 \\
\hline 1 & 0.68 & 0.70 & 0.70 & 0.69 \\
\hline 2 & 1.30 & 1.31 & 1.39 & 1.38 \\
\hline
\end{tabular}




\section{DISTRIBUTION}

\section{Number of Copies}

5

19

44

\section{U. S. Department of Energy}

Richland Operations Office

S. O. Branch \$7-54

W. F. Hendrickson S7-54

D. H. Irby S7-54

M. F. Jarvis $\quad$ S7-54

D. D. Wodrich $\$ 7-50$

Pacific Northwest Laboratory

J. W. Brothers

K9-20

S. A. Bryan

P7-25

L. L. Burger

P7-25

D. M Camaioni

$\mathrm{K} 2-38$

J. A. Campbell

P8-08

C. D. Carlson

P7-25

N. G. Colton

K3-75

C. H. Delegard

P7-25

A. R. Felmy

K8-97

M. A. Gerber

P8-38

R. T. Hallen

P8-38

M. A. Lilga

P8-38

L. R. Pederson

K2-44

$\mathrm{K} 2-44$

W. D. Samuels

R. D. Scheele

P7-25

C. S. Simmons

K9-33

J. M. Tingey

P7-25

J. J. Toth

K7-94

K. L. Wahl

P8-08

PHMC Team

G. S. Barney (10)

T5-12

T6-09

S7-14

D. R. Bratzel

S7-14

R. J. Cash

T5-12 


\section{DISTRIBUTION (cont)}

J. A. Compton

R. G. Cowan

F. R. Crawford

K. A. Gasper

J. M. Grigsby

D. L. Herting

B. E. Hey

J. R. Jewett

G. D. Johnson

S. A. Jones

N. W. Kirch

M. L. Klem

J. E. Meacham

S. G. Metcalf

N. G. McDuffie

J. C. Person

G. W. Reddick

D. A. Reynolds

M. J. Schliebe

J. P. Sloughter

L. M. Stock

C. S. Sutter

R. J. Thompson

A. B. Webb

W. I. Winters

Central Files

DPC

Document Processing and Distribution(2)
T5-12

R3-86

T5-50

G3-21

H4-62

T6-09

T6-09

T6-09

S7-15

T5-12

R2-11

H5-27

S7-14

T6-50

S7-15

T6-09

N1-26

R2-11

S4-25

T6-07

S7-14

T5-12

S6-19

H4-65

T6-50

A3-88

A3-94

A3-89 